ISSN: 0213-2060

DOI: https://doi.org/10.14201/shhme20193715378

\title{
ESCRIBIR EL ESPACIO ENTRE LA AUCTORITAS, LA LENGUA HABLADA Y EL RÉGIMEN AGRARIO: CAMPUS EN LOS FONDOS DOCUMENTALES DE WISSEMBOURG, LORSCH Y FULDA ENTRE EL SIGLO VIII Y MEDIADOS DEL IX
}

\author{
Writing the Space between Auctoritas, the Vernacular and the Agrarian \\ Regime: The Use of the Word Campus in the Eighth and Early-Ninth Century \\ Charters of Wissembourg, Lorsch and Fulda
}

Juan José LARREA

Depto. de Historia Medieval, Moderna y de América. Facultad de Letras. Universidad del País Vasco/Euskal Herriko Unibertsitatea. Paseo de la Universidad, 5. E-01006 VITORIA-GASTEIZ. C. e.: juanjose.larrea@ ehu.eus

Recibido: 2019-02-25

Revisado: 2019-04-08

Aceptado: 2019-04-30

RESUMEN: Este artículo estudia el uso de la palabra campus en los fondos de archivo carolingios de los monasterios de Wissembourg, Lorsch y Fulda anteriores a 840. Identifica los marcos de referencia de su utilización (textos patrísticos y exegéticos, lengua vernácula, formulae, percepción del paisaje agrario) y los distintos usos de cada scriptorium. El objetivo es comprender el sentido de un término, en apariencia transparente dentro del régimen agrario, en función de la lógica de producción de los documentos.

Palabras clave: Fuentes diplomáticas; Scriptoria; Carolingios; Espacios agrarios; Lenguas.

ABSTRACT: In this paper we examine the use of the word campus in the Carolingian charters of the monasteries of Wissembourg, Lorsch and Fulda before the year 840. We identify the different registers and frameworks in which it is employed (patristics, exegesis, the vernacular, formulae, perceptions of the agrarian landscape) and also distinguish between usages in the different scriptoria. The objective is to understand the meaning of a seemingly transparent term within the agrarian system and in relation to the logic behind the production of these charters.

Keywords: Charters; Scriptoria; Carolingians; Agrarian espaces; Languages. 
ESCRIBIR EL ESPACIO ENTRE LA AUCTORITAS, LA LENGUA HABLADA Y EL RÉGIMEN AGRARIO: CAMPUS EN LOS FONDOS DOCUMENTALES DE WISSEMBOURG, LORSCH Y FULDA... JUAN JOSÉ LARREA

SUMARIO: 0 Introducción. 1 El corpus documental. 2 La referencia de la auctoritas y la de la lengua hablada: campus/ager, feld/ackar. 3 En las colecciones de fórmulas: el díptico campis/terris (agris). 4 Campis/terris en las fórmulas de pertenencia de Lorsch, Wissembourg y Fulda. 5 Campus en los dispositivos. 6 Campus en la articulación entre los cultivos y los recursos del espacio inculto. 7 Una referencia meridional. 8 Conclusiones. 9 Referencias bibliográficas.

\section{INTRODUCCIÓN}

El objeto de esta contribución es estudiar el uso del término campus en algunos de los primeros grandes fondos de archivo altomedievales. En su origen está un programa de trabajo y discusión propuesto por Didier Panfili para reflexionar sobre el desciframiento de los textos y la espacialidad medievales a partir de un vocablo polisémico pero transparente y neutro en apariencia ${ }^{1}$. Campus, en efecto, no solo parece de significado evidente, sino que en algunos conjuntos documentales, entre los cuales está el que aquí vamos a tratar, es tan frecuente en las enumeraciones de las fórmulas de pertenencia (tam mansis, campis, pratis, pascuis, peruiis...) como rarísimo en los dispositivos de los textos. Este carácter de algún modo extremo en su aparente banalidad es, sin embargo, en buena medida lo que hace de esta palabra uno de los «monstruos semánticos» del vocabulario medieval del espacio ${ }^{2}$.

De modo más concreto, nos proponemos abordar, a través del análisis del uso de este vocablo en un conjunto documental, algunos elementos de la lógica que rige la descripción de los espacios agrarios en las fuentes diplomáticas altomedievales. Nuestro objetivo principal es distinguir los factores que condicionan los usos del término y observar sus interacciones. En lo que se refiere a los sistemas de representación, a la introducción del vocabulario vernáculo o a determinadas prácticas de escritura, como la manipulación de las colecciones de fórmulas, encontramos apoyo en diversas investigaciones antiguas y recientes. En cambio, el estudio de las prácticas de escritura altomedievales, con haber sido analizadas desde ángulos diversos ${ }^{3}$, apenas se ha interesado por el modo en que cada

1 El programa Campus impulsado por Didier Panfili (Lamop-París I) se materializó en tres encuentros habidos en París y Balaguer entre 2011 y 2013 (https://lamop.univ-paris1.fr/la-recherche-au-lamop/produire-ecrire-echanger/campus/ [13/11/2018]). Agradezco aquí a Roland Viader y Ernesto Pastor la lectura de la primera versión de este manuscrito y las correcciones que lo han mejorado, así como a los participantes en la reunión de 2017 del CTCPSM (Lamop, coordinado por Julien Demade) por sus aportaciones, y a Alain Guerreau por haber puesto a mi disposición los textos digitalizados de la edición del Codex Laureshamensis. Este trabajo se ha hecho dentro del grupo GIU17/006 y en el marco del proyecto Scriptoria, lenguajes y espacio agrario en la Alta Edad Media (HAR2017-86502-P).

2 La expresión es de Guerreau, Alain. «Quelques caractères spécifiques de l'espace féodal européen». En Bulst, Neithard et al. (ed.). L'État ou le Roi. Les fondations de la modernité monarchique en France (XIV'-XVIT siècle). Paris: Éditions de la Maison des Sciences de l'Homme, 1996, pp. 85-101. Véase también Lauwers, Michel y Ripart, Laurent. «Représentation et gestion de l'espace dans l'Occident médiéval». En GenEt, Jean-Philippe (dir.). Rome et l'État moderne européen. Rome: École Française de Rome, 2007, pp. 115-171.

3 Por ejemplo, BoRgolte, Michael. Geschichte der Grafschaften Alemanniens in fränkischer Zeit. Sigmaringen: Thorbecke, 1984, cap. 2; MсKiтTERick, Rosamond. The Carolingians and the written word. 
ESCRIBIR EL ESPACIO ENTRE LA AUCTORITAS, LA LENGUA HABLADA Y EL RÉGIMEN AGRARIO: CAMPUS EN LOS FONDOS DOCUMENTALES DE WISSEMBOURG, LORSCH Y FULDA... JUAN JOSÉ LARREA

scriptorium se enfrenta a la descripción del paisaje agrario, siendo así que este parece un paso indispensable de cara a la explotación de estas fuentes para la historia rural. Pretendemos aquí acercarnos a cómo la organización del terrazgo y las articulaciones entre los componentes del espacio agrario modulan la terminología y fraseología de los escribas.

Este artículo se ordena en cuatro partes. En la primera, tras presentar las fuentes, nos ocuparemos de los marcos de referencia: por un lado, confrontaremos los usos de campus en los textos de la auctoritas con los de la lengua vernácula; por otro lado, examinaremos la utilización del término en las colecciones de fórmulas que constituyen el cañamazo sobre el que se construyen los diplomas. La segunda parte es una aproximación comparada a la práctica de cada scriptorium, distinguiendo para ello la manipulación de las fórmulas de pertenencia del modo en que campus es tratado en los dispositivos: el fin es acercarnos a la percepción de los espacios agrarios. La tercera parte se interesa por la relación entre el uso de campus y una práctica agraria específica que articula los cultivos con la explotación de los espacios incultos. La cuarta, en fin, busca contrastar algunas conclusiones de los puntos anteriores con fondos de otras regiones y señalar algún elemento distintivo de las áreas de lengua hablada latina.

\section{EL CORPUS DOCUMENTAL ${ }^{4}$}

El interés de los primeros grandes fondos de archivo altomedievales, es decir los producidos en abadías y obispados del alto y medio Rin, Baviera y Hesse, reside, por un lado, en el importante número de documentos redactados sin solución de continuidad durante al menos un par de generaciones y, por otro, en el hecho de que se trata de las más antiguas series de descripciones del paisaje agrario disponibles en Occidente.

El corpus aquí seleccionado resulta de un compromiso entre este interés y la necesidad de asegurar una coherencia territorial y cronológica básica. Se trata de los fondos anteriores a 840 de los monasterios de Wissembourg, Lorsch y Fulda. Con tener orígenes diversos, los tres son piezas de primer orden del entramado institucional carolingio ${ }^{5}$. Para lo que nos interesa aquí, las zonas sobre las que estos archivos monásticos arrojan luz forman un arco

Cambridge: Cambridge University Press, 1989; ERHARt, Peter et al. (eds.). Die Privaturkunden der Karolingerzeit. Dietikon-Zürich: Urs Graf, 2009.

4 Siglas: CDF = Dronke, Ernst Friedrich Johann. Codex Diplomaticus Fuldensis. Aalen: 1962 [Kassel, 1850']; ChSG = Erhart, Peter et al. Chartularium Sangallense. Band I (700-840). St. Gallen: Herausgeber und Verlagsgemeinschaft Chartularium Sangallense-Thorbecke, 2013; CL = GLöCKner, Karl. Codex Laureshamensis. Darmstadt: 1929-1936; MF = Zeumer, Karl (ed.). «Marculfi Formulae». En Formulae Merowingici et Karolini aevi, MGH, Legum sectio V. Hannover: Hahn, 1886; TW = Doll, Anton. Traditiones Wizenburgenses: Die Urkunden des Klosters Weissenburg, 661-864. Darmstadt: Hessische Historische Kommission Darmstadt, 1979; UF = STENGEL, Edmund Ernst. Urkundenbuch des Klosters Fulda. Marburg: Historische Kommission für Hessen und Waldeck, 1956-1958.

5 Wissembourg, en Alsacia, es una fundación de hacia 660 debida a un grupo aristocrático emparentado con los que serán los carolingios y al obispo de Espira. Lorsch, en la margen derecha del Rin, a la altura de Worms, fue fundado por una familia aristocrática del más alto rango en 764, para pasar al patronato real en 772. Fulda surgió en Hesse en 744 en el contexto de la misión de Bonifacio; obtuvo el privilegio de inmunidad en 774 . 
ESCRIBIR EL ESPACIO ENTRE LA AUCTORITAS, LA LENGUA HABLADA Y EL RÉGIMEN AGRARIO: CAMPUS EN LOS FONDOS DOCUMENTALES DE WISSEMBOURG, LORSCH Y FULDA...

territorial compacto que se extiende desde los Vosgos hasta la selva de Turingia, a ambos lados del Medio Rin (figura 1). Desde el punto de vista del marco cronológico, el que Wissembourg conserve algunos documentos de antigüedad notable, siendo el más temprano de 661, parece estirarlo en extremo, pero en realidad la eclosión de la producción sostenida de documentos tiene lugar, al igual que en Lorsch y Fulda, en las décadas centrales del siglo viII. En cuanto al hito final, 840 es naturalmente una fecha convencional escogida por motivos prácticos: nos permite abarcar los tomos que quedan del cartulario de Fulda, la espectacular ola de producción documental del último tercio del siglo viII en Lorsch y también la mayor parte de lo que ha transmitido el cartulario de Wissembourg. Ha de tenerse en cuenta que la expansión patrimonial y por ende la curva de producción documental de estas instituciones en época carolingia se caracteriza por un ascenso fulgurante que se desploma de un modo casi igual de brusco al cabo de un par de generaciones. Por dar una referencia global, entre las tres y para el período que seguimos, vienen a sumar la mitad del total de 10.000 documentos calculados grosso modo por Fred Schwind como conservados para toda la época carolingia en las regiones de lengua alemana ${ }^{6}$.

De Wissembourg se conserva, en lo que se refiere a las fuentes diplomáticas, el Codex Traditionum, compuesto entre 855 y 860 . Muy probablemente es el superviviente de un gran cartulario en varios tomos organizado por regiones. Ha transmitido 275 documentos referidos a los pagi de Alsacia, el Sarre y el Saulnois, de los cuales 247 corresponden a nuestro marco cronológico ${ }^{7}$.

La documentación de Lorsch se ha transmitido a través del Codex Laureshamensis. Elaborado entre 1170 y 1195, muy posiblemente sobre la base de un cartulario carolingio perdido ${ }^{8}$, comprende 3.304 documentos anteriores a 840 , donaciones en su inmensa mayoría, de los cuales 2.680 datan de la segunda mitad del siglo viII ${ }^{9}$. Estas cifras apabullantes precisan de todos modos de alguna matización, porque la calidad de las copias del códice empieza a degradarse pasados los primeros novecientos documentos. A partir de ahí el cartulario va convirtiéndose en una colección de extractos muy abreviados. Como el conjunto está organizado por territorios, el resultado es una información excelente para los pagi de la margen derecha del Rin inmediatos al monasterio y notablemente irregular para el resto ${ }^{10}$.

6 Schwind, Fred. «Beobachtungen zur inneren Struktur des Dorfes in karolingischer Zeit». En Jankhun, Herbert et al. (eds.). Das Dorf der Eisenzeit und des frühen Mittelalters. Göttingen: Vandenhoeck \& Ruprecht, 1977, pp. 444-493 (pp. 446-448). Una visión de conjunto de los cartularios renanos, LoHRManN, Dietrich. «Évolution et organisation interne des cartulaires rhénans du Moyen Âge». En GuYotjeanniN, Olivier et al. (eds.). Les cartulaires: actes de la table ronde organisée par l'École Nationale des Chartes et le G.D.R. 121 du C.N.R.S. Paris: École des Chartes, 1993, pp. 79-90.

7 La edición de Anton Doll (TW) es impecable por su meticulosidad y por la riqueza del estudio diplomático que la acompaña.

8 STAAB, Franz. «Aspekte der Grundherrschaftsentwicklung von Lorsch vornehmlich aufgrund der Urbare des Codex Laureshamensis». En Rösener, Werner (ed.). Strukturen der Grundherrschaft im frühen Mittelalter. Göttingen: Vandenhoeck \& Ruprecht, 1993, pp. 285-334 (pp. 294-296).

9 Selzer, Wolfgang. «Der Grundbesitz des Klosters Lorsch». En Laurissa Jubilans. Festschrift zur 1200-Jahrfeier von Lorsch. Lorsch: Gemeinde Lorsch, 1964, pp. 64-70 (p. 65).

10 Tenemos la cuidadosa y erudita edición de Karl Glöckner (C L). Esta edición está ahora disponible en línea, con la posibilidad además de confrontarla con las imágenes del Codex y con una utilidad de localización cartográfica: https://archivum-laureshamense-digital.de/view/saw_mainz72/0001/image (08/11/2018). 
ESCRIBIR EL ESPACIO ENTRE LA AUCTORITAS, LA LENGUA HABLADA Y EL RÉGIMEN AGRARIO: CAMPUS EN LOS FONDOS DOCUMENTALES DE WISSEMBOURG, LORSCH Y FULDA...

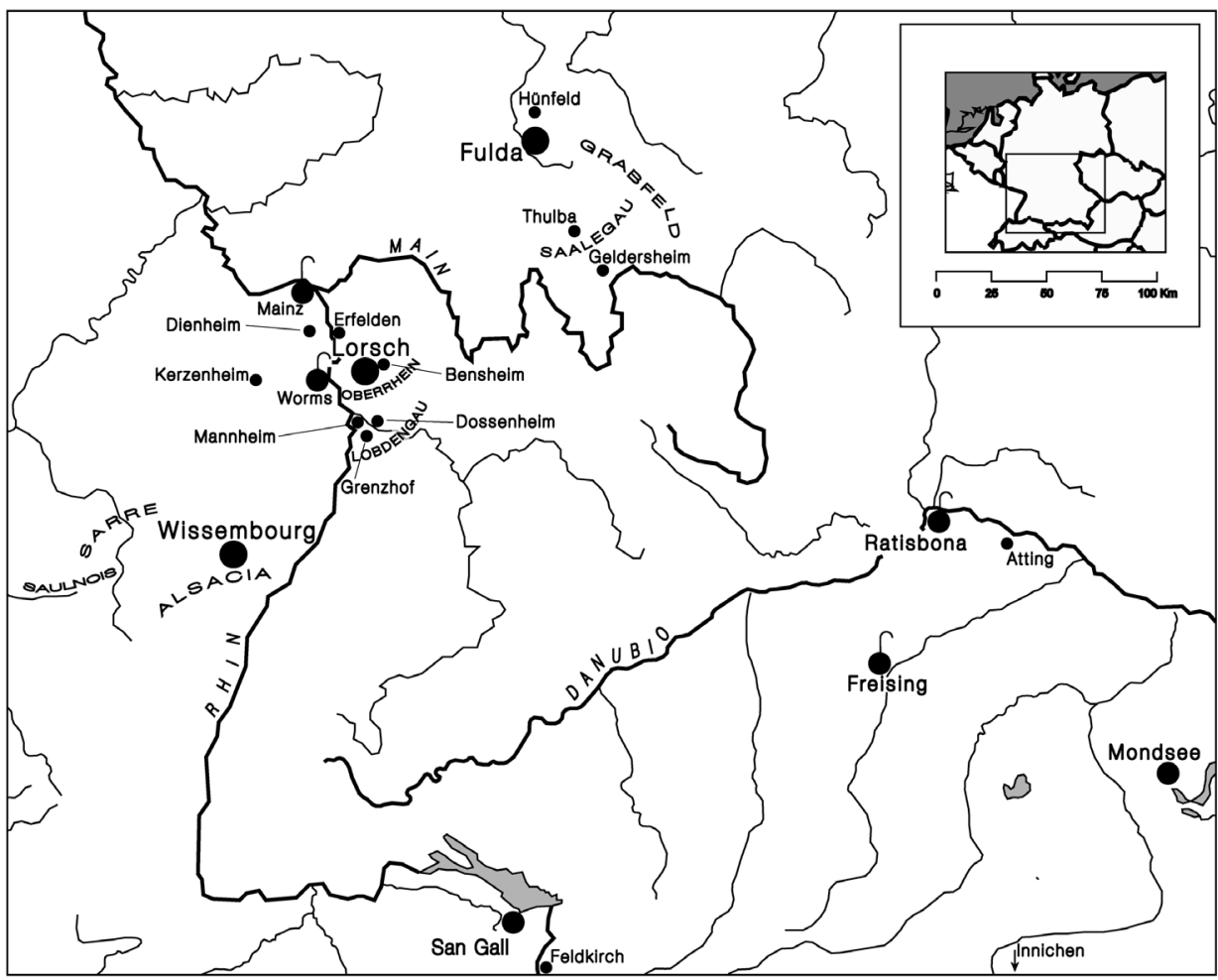

FIGURA 1. Mapa de situación de los monasterios, obispados, territorios y lugares mencionados en el texto.

En fin, del gran cartulario compuesto en Fulda por mandato de su abad Rabano Mauro, entre 828 y 833 , solo ha llegado hasta nosotros el contenido de dos tomos, uno en su forma original, el llamado «cartulario de Rabano», y otro, el «cartulario de Pistorius», gracias a la edición que hizo el humanista de este nombre en 1607. El primero recoge esencialmente las donaciones recibidas al oeste del Rin, sobre todo en Mainz - $\mathrm{O}$ Maguncia- y su territorio, mientras que el segundo cubre zonas cercanas al monasterio, en particular los pagi de Grabfeld y Saalegau. La documentación de estos dos tomos del cartulario de Fulda presenta la peculiaridad de provenir globalmente de sendos focos de producción escrita muy distintos entre sí: la expansión patrimonial de la zona de Mainz, de donde es el primer círculo de amigos y aliados del monasterio, fue registrada no por los escribas de Fulda, sino por «escribas públicos»-según la denominación de la historiografía alemana- de la ciudad, vinculados sin duda a la sede episcopal, luego arzobispal. En cambio, las donaciones próximas al monasterio, en general algo más tardías, fueron llevadas al pergamino en el scriptorium monástico ${ }^{11}$. Los usos de unos y otros en

11 Freise, Eckhard. «Studien zum Einzugsbereich der Klostergemeinschaft von Fulda». En ScHMID, Karl (ed.). Die Klostergemeinschaft von Fulda im früheren Mittelalter. München: Fink, 1978, pp. 1003-1269 
ESCRIBIR EL ESPACIO ENTRE LA AUCTORITAS, LA LENGUA HABLADA Y EL RÉGIMEN AGRARIO: CAMPUS EN LOS FONDOS DOCUMENTALES DE WISSEMBOURG, LORSCH Y FULDA...

relación al paisaje agrario son muy diferentes. En total, los dos tomos supervivientes han transmitido una cuarta parte de los 2.000 documentos que se copiaron en el conjunto del cartulario ${ }^{12}$. Para los que se han perdido solo disponemos de los extractos, bastante problemáticos, que hizo el monje Eberhard hacia 1160 en el llamado Codex Eberhardi ${ }^{13}$.

2 LA REFERENCIA DE LA AUCTORITAS Y LA DE LA LENGUA HABLADA: CAMPUS/AGER, FELD/ ACKAR

Tratándose de abordar los sentidos de campus en el sistema de representación de los textos de la auctoritas, la obra de Rabano Mauro nos ofrece un mirador privilegiado, en la medida en que recoge numerosos textos exegéticos y patrísticos salidos de la pluma de un actor principal de la expansión de Fulda. De acuerdo con el buscador de la Patrologia Latina Database, Rabano Mauro utiliza 110 veces la palabra campus en sus escritos. Por otro lado, ager, que debe necesariamente examinarse si se quiere aprehender los significados de campus, aparece en 200 ocasiones. Más allá de los usos genéricos compartidos por ambos términos, relativos al medio rural en general o al territorio de un pueblo -en el sentido de grupo étnico- o de una ciudad, campus presenta una connotación muy marcada de espacio llano y abierto, opuesto a la montaña y el bosque. Ager, en cambio, no se asocia a representaciones topográficas, sino a las nociones de trabajo y posesión: a diferencia de los campi, los agri son labrados, cosechados, comprados o deseados.

Esta distinción es ya muy clara en la Vulgata ${ }^{14}$ y sin duda no es una originalidad de Rabano Mauro: campus est terrarum planities (Etym. 14, 8) según Isidoro, quien explica en cambio la etimología de ager porque in eo agatur aliquid (Etym. 15, 13). En cualquier caso, el contraste es tan productivo en Rabano Mauro que determina el uso de campus y ager en sentido espiritual o alegórico: durante la tentación de Cristo, la montaña representa la soberbia del diablo, mientras que el descenso ad campestria significa la elección divina de la humildad ${ }^{15}$. Una asimilación igualmente positiva aparece en la evocación de los amplissimos campos de las Sagradas Escrituras ${ }^{16}$. En cambio, el

(pp. 1091-1092 y 1177-1178); RaAijmakers, Janneke. The Making of the Monastic Community of Fulda, c. 744-c. 900. Cambridge: Cambridge University Press, 2012, pp. 198 y ss.

12 STENGel, Edmund Ernst. "Über die karlingischen Cartulare des Klosters Fulda (Fuldensia II)». En Stengel, Edmund Ernst. Abhandlungen und Untersuchungen zur Hessischen Geschichte. Marburg: Elwert, 1960, pp. 147-193 (pp. 148-150).

13 La edición de los fondos de Fulda es muy desigual. La de Edmund Ernst Stengel (UF) es erudita y de calidad, pero solo llega hasta 802. Para el resto, sigue siendo necesario acudir a la edición de Ernst F. J. Dronke de mediados del siglo XIx, que presenta notables deficiencias (CDF). El Codex Eberhardi dispone en cambio de una edición reciente: Meyer zu Ermgassen, Heinrich. Der Codex Eberhardi des Klosters Fulda. 4 vols. Marburg: Elwert, 1995-2009. El último volumen corresponde al facsímil del códice.

14 Hemos utilizado las concordancias disponibles en línea en http://www.intratext.com/IXT/ LAT0001/ [12/11/2018]. La pertinencia de examinar campus y ager en la Vulgata forma parte de las propuestas de Didier Panfili en el proyecto Campus (supra n. 1), en la línea de otros autores como Alain Guerreau o Joseph Morsel.

15 In Matthaeum I, iv (PL 107, col. 784A).

16 In Epistolas Beati Pauli V, viii (PL 111, col. 1476C). 
ESCRIBIR EL ESPACIO ENTRE LA AUCTORITAS, LA LENGUA HABLADA Y EL RÉGIMEN AGRARIO: CAMPUS EN LOS FONDOS DOCUMENTALES DE WISSEMBOURG, LORSCH Y FULDA... JUAN JOSÉ LARREA

ager espiritual se asocia a acciones simbólicas como la simiente, la cosecha o el desbroce de las spinae vitiorum ${ }^{17}$.

Dicho esto, conviene tener la precaución de recordar que cada esfera de uso de la lengua tiene sus condicionantes propios y que no cabe imaginar automatismos, como ilustra un ejemplo que podemos extraer del mismo Rabano Mauro. En su comentario de la escena que precede al asesinato de Abel (Génesis 4, 8), el interés de este autor por considerar la exégesis de versiones bíblicas distintas de la Vulgata le lleva a yuxtaponer en cierto momento una frase de esta, que emplea ager, y una frase tomada de la Vetus Latina, que utiliza campus, lo que le conduce a tratar como perfectamente equivalentes uno y otro término: Transeamus in campum. Cumque essent in agro ${ }^{18}$. No identificamos una suerte de patrón intocable, sino un marco de referencia.

Si volvemos la mirada a la lengua vernácula, vemos que la práctica de la traducción de época carolingia muestra una doble correlación de campus a feld y de ager a ackar. Glosarios y textos en alto alemán antiguo traducen sistemáticamente campus por feld ${ }^{19}$. En este mismo sentido, el Glosario del Génesis de Reichenau traduce la palabra campestria a que nos hemos referido en el párrafo anterior por frauildi, una palabra formada sobre feld. Otros testimonios no constreñidos por las exigencias de la traducción de los textos sagrados confirman el sentido de feld. Así, por ejemplo, la lista bilingüe del pequeńo códice llamado Vocabularius St. Galli distingue dos minúsculos grupos de palabras relativas al paisaje rural ${ }^{20}$ : holz (silua) y uualt (ermis) se refieren al espacio del bosque, mientras que el de los cultivos cuenta con tres términos: piunte corresponde a cluasara (sic), feld a campus y accar a ager. Feld (campus) se distingue, pues, del bosque, pero también del espacio cercado y de ager/acker, de cuyo significado nos ocuparemos inmediatamente. Igualmente, la versión en alto alemán antiguo de la Ley Sálica traduce campus por feld en el sentido amplio de espacio rural abierto y no necesariamente cultivado ${ }^{21}$. La toponimia confirma esta acepción amplia y no estrictamente ligada al trabajo concreto: se encuentra

17 In Proverbia Salomonis I, xxiv (PL 111, col. 760A).

18 La Vetus Latina repite campus: transeamus in campum et [factum est] cum/dum essent ipsi in campol campum: Fischer, Bonifatius (ed.). Vetus Latina. Die reste der altlateinischen Bibel. 2. Genesis. Freiburg: Herder, 1951-1954, p. 83. La Vulgata no presenta ni repetición ni sinónimo: Egrediamur foras. Cumque essent in agro.

9 Como referencia general, SEeBold, Elmar. Chronologisches Wörterbuch des deutschen Wortschatzes. 2. Der Wortschatz des 9. Jahrhunderts. Berlin-New York: De Gruyter, 2008, pp. 128-129 (ackar) y 291-292 (feld); y Tiefenbach, Heinrich. «Bezeichnungen für Fluren im Althochdeutschen, Altsächsischen und Altniederfränkischen». En BECK, H. et al. (ed.). Untersuchungen zur eisenzeitlichen und frühmittelalterlichen Flur in Mitteleuropa und ihrer Nutzung. Göttingen: 1980, pp. 287-322 (pp. 304 y ss.). Ver también KarG-GasTERStÄDt, Elisabeth y Frings, Theodor. Althochdeutsches Wörterbuch. Berlin: Akademie-Verlag, 1968, pp. 90-93 (acker), 709-715 (feld) y 1204 (frafildi); LADE, Ulrike. Flur und Feld. Volkssprachige Bezeichnungen in den frühmittelalterlichen Leges. Münster: Phil. Fak. Diss., 1987, pp. 125-129.

20 Steinmeyer, Elias y Sievers, Eduard. Die althochdeutschen Glossen. 1. Glossen zu biblischen Schriften. Berlin: Weidmann, 1879; SeEBold, Elmar. Chronologisches Wörterbuch des deutschen Wortschatzes. Der Wortschatz des 8. Jahrhunderts (und früheren Quellen). Berlin-New York: De Gruyter, 2001, pp. 58 y ss.

21 En el pasaje Si quis porcellum in campo inter porcos ipso porcario custodiente furauerit (LS 51, 4), in felde traduce in campo: Sonderegger, Stefan. «Die althochdeutsche Lex Salica-Übersetzung». En LAufNER, Richard (ed.). Festgabe für Wolfgang Jungandreas zum 70. Geburtstag am 9. Dezember 1964. Beiträge zur deutschen Sprachgeschichte, Landes-, Volks- und Altertumskunde. Trier: Neu, 1964, pp. 113-122. 
ESCRIBIR EL ESPACIO ENTRE LA AUCTORITAS, LA LENGUA HABLADA Y EL RÉGIMEN AGRARIO: CAMPUS EN LOS FONDOS DOCUMENTALES DE WISSEMBOURG, LORSCH Y FULDA...

60 JUAN JOSÉ LARREA

-feld en nombres de pueblos (Erfelden) ${ }^{22}$, de vastos espacios de tierra fiscal (campo qui dicitur Unofelt) ${ }^{23} \mathrm{e}$ incluso de distritos o pagi (Wormazfeld $)^{24}$.

En cuanto a ager, se traduce por ackar tanto en la Vulgata como en otros textos, por ejemplo la regla de San Benito. De que no se trata en ningún caso de una práctica inducida por la semejanza de las palabras latina y germánica dan fe múltiples menciones en contextos independientes de la glosa y la traducción. Los historiadores de la lengua han constatado ampliamente que ackar está muy fuertemente connotado por la noción de trabajo agrícola, mientras que tal cosa no ocurre en los testimonios de feld. Así, zi ackare gangan (gangan: gehen) significa "trabajar la tierra»", del mismo modo que ackarmann (excepcionalmente ackarbigangari) es la palabra más usual para designar al trabajador agrícola. Es más, este vocablo seguirá en uso hasta bastante más acá de la Edad Media ${ }^{26}$. Otro contraste con feld se aprecia en la ausencia de acker como correspondiente de ager en el sentido de circunscripción ${ }^{27}$ : ager tiene un ámbito semántico más amplio y por ello él y acker se recubren de modo más incompleto que lo hacen campus y feld.

\section{EN laS COLECCIONES DE FóRMULAS: El DíPtico CAMPIS/TERRIS (AGRIS)}

Las colecciones de fórmulas son evidentemente la referencia práctica inmediata para quienes redactan los diplomas. Puesto que en estas colecciones los términos que nos interesan se encuentran casi exclusivamente en las enumeraciones de bienes y, por tanto, aparecen declinados en ablativo plural, una primera aproximación puede hacerse muy cómodamente con la ayuda del buscador de la edición en línea de los Monumenta. De este sondeo resulta que en el conjunto de las colecciones de épocas merovingia y carolingia la palabra más abundante es terris con 126 menciones, seguida de campis con 53 y de las escasas 12 menciones de agris. He aquí una divergencia con respecto a los usos de los textos de la auctoritas: ager es muy poco frecuente en las fórmulas. Sin pretensión alguna de aportar una explicación global a este hecho, es interesante evocar aquí el testimonio del Glossarium Biblicum, redactado seguramente en el norte de la Galia en el siglo viII. Se ordenan en él por parejas palabras latinas consideradas como de difícil comprensión y palabras consideradas como sinónimos más accesibles (por ejemplo, dico para entender aio, o vasa aquarum por idria). Pues bien, el Glossarium cataloga ager como difícil y propone

22 CL 198, por ejemplo.

23 UF 146. En este caso, cabe preguntarse si la traducción no ha ido en sentido inverso, de modo que campus traduce el felt integrado en el topónimo. Sobre el Hünfeld, Gockel, Michael. «Die Träger von Rodung und Siedlung im Hünfelder Raum in karolingischer Zeit». Hessisches Jabrbuch für Landesgeschichte, 1976, vol. 26, pp. 1-24.

24 Por ejemplo, UF 210, pero es muy corriente en las actas de Fulda.

25 Seebold, Wortschatz 2, p. 129.

26 Bergmann, Rolf. «Althochdeutsche Glossen zu "Bauer"». En Wenskus, Reinhard et al. (ed.). Wort und Begriff "Bauer". Göttingen: 1975, pp. 89-127.

27 BANGE, François. "L'ager et la villa: structures du paysage et du peuplement dans la région mâconnaise à la fin du haut Moyen Âge ( $\mathrm{IX}^{\mathrm{e}}-\mathrm{XI}^{\mathrm{e}}$ siècles)». Annales. Économies, Sociétés, Civilisations, 1984, vol. 39, pp. 529-569; VIADER, Roland. «Introduction». Annales du Midi (=Vigueries et autres circonscriptions intermédiaires du haut Moyen Âge, dir. Roland Viader), 2009, vol. 121, pp. 149-157. 
ESCRIBIR EL ESPACIO ENTRE LA AUCTORITAS, LA LENGUA HABLADA Y EL RÉGIMEN AGRARIO: CAMPUS EN LOS FONDOS DOCUMENTALES DE WISSEMBOURG, LORSCH Y FULDA... JUAN JOSÉ LARREA

campus como la forma inteligible correspondiente ${ }^{28}$. El proceso de práctica diplomática, selección y transmisión que da lugar a las colecciones de fórmulas, en cambio, parece haber buscado la solución sustituyendo agris por terris.

En efecto, si examinamos las relaciones entre los tres términos, observamos rápidamente un juego de asociaciones y exclusiones en el que campis aparece generalmente acompañado de otro elemento, siendo este terris casi siempre o agris ocasionalmente:

hoc est tam terris, mansis, una cum superpositis domibus, aedificiis, vineis, silvis, campis, pratis, pascuis, cultis et incultis adiacentiisque, hominibus, aquis aquarumve decursibus, una cum mancipia tanta (Cartae Senonicae 31).

En cambio, agris y terris se excluyen mutuamente ${ }^{29}$; o, mejor expresado, terris excluye casi siempre a ager.

Conviene prestar una atención especial a la colección de Marculfo, puesto que es la que nuestros scriptoria utilizan generalmente ${ }^{30}$. Sobre ella pueden anotarse dos observaciones. En primer lugar, en las 52 fórmulas del título correspondiente al tipo de actas que nos interesa, de Cartis Pagensis, campus figura de dos modos bien distintos: cuando las fórmulas no se preocupan de la descripción de los bienes concernidos por el acto jurídico, campus aparece en enumeraciones que incluyen también terris según el modelo del que acabamos de reproducir un ejemplo. Esto ocurre tanto en el caso de las donaciones ${ }^{31}$ como en los de las ventas o trueques de villa $e^{32}$. El valor como noción englobante del término villa justifica sin duda la ausencia de detalles. Ahora bien, cuando se trata de vender o intercambiar parcelas, y por tanto cuando el registro de la superficie y los límites se hace necesario, el término escogido para designar el objeto del contrato es campus $^{33}$ :

convenit inter illo et illo, ut terra aliqua, aut prata, aut vineas, seo qualibet, inter se commutare deberint; quod ita et fecerunt. Dedit igitur ille illius campo in loco nuncupante illo, habente tantum, qui subiungit a latere uno ill., ab alio latere, aut fronte, illius (MF II, 24).

Más que la naturaleza del acto jurídico, es la necesidad de precisión descriptiva lo que saca a campus de la fórmula de pertenencia para emplearlo en la identificación de la parcela concreta. Obsérvese que esta se describe en función de sus límites y no del trabajo que se le aplica, en lo que aparece un elemento de coherencia con la noción de campus según vimos en la exégesis bíblica y la patrística.

28 Klein, Hans-W. Die Reichenauer Glossen. 1. Einleitung, Text, vollständiger Index und Konkordanzen. München: Hueber, 1968, p. 75.

29 La única excepción es Form. Augienses, col. B, 25, pero se explica porque se refiere a la categoría específica de terra salica.

30 Zatscheк, Heinz. «Die Benutzung der Formulae Marculfi und anderer Formularsammlungen in den Privaturkunden des 8. bis 10. Jahrhunderts». Mitteilungen des Österreichischen Instituts für Geschichtsforschung, 1927 , vol. 42, pp. 165-267.

31 MF II, 3, 4, 6, 7, 10 y 11.

32 MF II, 19 y 23.

33 MF II, 21 y 24. 
ESCRIBIR EL ESPACIO ENTRE LA AUCTORITAS, LA LENGUA HABLADA Y EL RÉGIMEN AGRARIO: CAMPUS EN LOS FONDOS DOCUMENTALES DE WISSEMBOURG, LORSCH Y FULDA... JUAN JOSÉ LARREA

En segundo lugar, y en relación a la práctica de los escribas, cabe subrayar que el título I de Marculfo, aun presentando también la pareja campis/terris en algunas enumeraciones ${ }^{34}$, sugiere de alguna manera procedimientos de simplificación de estas últimas: hay una fórmula que suprime terris ${ }^{35}$, frente a tres que, por el contrario, eliminan campis de enumeraciones particularmente escuetas ${ }^{36}$. Esta vía de reducción también es visible en otras colecciones, particularmente en la de Reichenau, aunque la coexistencia de campis y terris siga siendo la norma habitual.

\section{Campis/terRIS En las fórmulas de pertenencia de LORSCH, Wissembourg y FULDA}

Enfrentados a la descripción de los componentes del paisaje agrario y las estructuras fundiarias, ¿`cómo conectan los escribas los términos de las fórmulas con los de la lengua hablada? ¿Cómo y en qué medida los asocian al sistema de representación de los textos de la auctoritas? Ignoramos todo de esta operación mental y de las formas particulares que se adoptaban en cada región, en cada escritorio e incluso en cada ánimo individual. Pero, por mucho que todo eso se nos escape, el análisis de la práctica no deja de estar a nuestro alcance. Las series de documentos de nuestras tres abadías son lo suficientemente nutridas como para permitirnos identificar algunos criterios en la manipulación de las fórmulas de pertenencia, en este caso en lo que se refiere a la pareja campis/terris ${ }^{37}$.

Empecemos por el conjunto documental más imponente. En la segunda mitad del siglo VIII, la expansión patrimonial de Lorsch dio lugar a un ritmo de composición de diplomas que alcanzó el centenar anual de media durante los ocho primeros años ${ }^{38}$. Bajo el gobierno de los tres primeros abades (765-804), tres escribas redactaron en abundancia y dirigieron la actividad del escritorio ${ }^{39}$. El primero, Samuel (766-795), fue de algún modo el notario del éxito del monasterio. Bien conocido por los especialistas de la diplomáti$\mathrm{Ca}^{40}$, Samuel sigue de cerca las enumeraciones de Marculfo sin dejar por ello de modificarlas cuando lo juzga conveniente. En lo que se refiere al díptico campis/terris, Samuel

34 MF I, 13, 14 y 33.

35 MF I, 30.

36 MF I, 12, 15 y 36.

37 A propósito de la lógica que preside la manipulación de las fórmulas de pertenencia, ZATSCHEK, «Formulae»; Zimmermann, Michel. «Glose, tautologie ou inventaire? L'énumération descriptive dans la documentation catalane du $\mathrm{x}^{\mathrm{e}}$ au XII ${ }^{\mathrm{e}}$ siècle». Cahiers de Linguistique Hispanique Médiévale, 1989, vol. 14-15, pp. 309-338; Zimmermann, Michel. Écrire et lire en Catalogne (IX'-XIt siècle). Madrid: Casa de Velázquez, 2003, pp. 206 y ss.; Chastang, Pierre. «La langue, l'écriture et l'histoire. La singulière Catalogne de Michel Zimmermann». Médiévales, 2007, vol. 52, pp. 171-180; García de CortázAr, José Ángel y Agúndez, Leticia. "Memoria y cultura en la documentación del monasterio de Celanova: la respuesta de las "fórmulas inútiles” (años 842-1165)». En Val Valdivieso, M.a Isabel del y Martínez Sopena, Pascual (eds.). Castilla y el mundo feudal: homenaje al profesor Julio Valdeón. Valladolid: Junta de Castilla y León, 2009, pp. 251-267.

38 Selzer, "Grundbesitz», p. 64.

39 LARreA, Juan José. «L'autre visage du manse. Actes de la pratique et structures agraires dans la vallée du Rhin moyen au viII ${ }^{\mathrm{e}}$ siècle». Frühmittelalterliche Studien, 2012, vol. 46, pp. 41-98.

40 Zatscheк, «Formulae», pp. 179-180. 
ESCRIBIR EL ESPACIO ENTRE LA AUCTORITAS, LA LENGUA HABLADA Y EL RÉGIMEN AGRARIO: CAMPUS EN LOS FONDOS DOCUMENTALES DE WISSEMBOURG, LORSCH Y FULDA... JUAN JOSÉ LARREA

no duda en simplificarlo con cierta frecuencia: de un total de cuarenta actas que incluyen estas enumeraciones, elimina campis una sola vez ${ }^{41}$ y terris en cambio quince veces ${ }^{42}$. Tras él, Grimmarius (775-792 ${ }^{43}$ prosigue y acentúa la misma tendencia: suprime terris nueve veces de las diez actas en las que emplea este tipo de fórmula ${ }^{44}$. Finalmente, Reginbert (785-806), escriba principal durante la transformación de Lorsch en gran foco cultural, actúa del mismo modo y elimina terris diecinueve veces de veintidós ${ }^{45}$. En suma, no estamos ante un tratamiento aleatorio de palabras huecas de sentido en enumeraciones copiadas mecánicamente, sino de una decisión consciente que acaba afirmándose como uso del escritorio de Lorsch. Fueran cuales fuesen sus razones, estos hombres, a la hora de listar componentes de un patrimonio fundiario, no encontraron pertinente conservar campis y terris en la misma enumeración.

En cuanto a Wissembourg, el gráfico adjunto (figura 2), ampliamente facilitado por los análisis diplomáticos de la edición de Anton Doll ${ }^{46}$, tiene, creemos, el interés de hacer visible la coherencia en el tiempo de los usos de escritura y el papel concreto de los diferentes escribas. Muestra la evolución de campis/terris en las fórmulas de pertenencia durante un largo siglo viII. Se distingue bien un uso anterior a la eclosión patrimonial ocurrida con los primeros carolingios, en la que campis sola o con terris está presente en la mayoría de los documentos, mientras que terris raramente aparece sola. En la fase siguiente, las proporciones se invierten y es terris sola o con campis la que aparece regularmente, mientras que las menciones de campis sola en las enumeraciones se hacen muy escasas bajo el mandato del abad Ermbert (764-793). Entre los escribas de Wissembourg se observa, pues, la misma percepción que en Lorsch sobre lo innecesario de mantener ambos términos en las fórmulas de pertenencia, si bien los primeros han optado por dos soluciones sucesivas distintas.

Por su parte, los fondos de Fulda muestran un comportamiento más fiel a las colecciones de fórmulas. Entre los escribas públicos de Mainz no se llega a apreciar una tendencia clara, si bien algunos suprimen esporádicamente campis de las enumeracio$n^{n} s^{47}$. En el escritorio monástico se mantienen también los dos términos. Curiosamente, el escriba principal de la primera oleada de donaciones de zonas cercanas al monasterio, Asger (776-798), empieza a actuar como los de Lorsch eliminando terris en algunas actas del final de su vida activa ${ }^{48}$. Por esos mismos ańos, su trabajo se solapa con el de su sucesor, Hracholf, quien parece vacilar entre mantener la pareja de términos o eliminar terris.

41 CL 899.

42 CL 178, 239, 315, 441, 486, 538, 540, 552, 702, 713, 899, 942, 948, 999, 1046 y 1083.

43 Las etapas de actividad de los escribas se solapan naturalmente. La aparente incongruencia de las de Grimmarius con respecto a las de Samuel se debe a que este último, tras haber redactado la mayor parte de sus diplomas bajo el gobierno del abad Gundeland (765-778), siguió escribiendo esporádicamente hasta 795.

44 CL 202, 322, 326, 462, 501, 502, 521, 762 y 912

45 CL 184, 207, 211, 214, 215, 256, 351, 356, 413, 421, 472, 506, 584, 745, 765, 793, 816, 837 y 888.

46 Doll, Traditiones Wizenburgenses, pp. 596-603.

47 Wolfram una vez (UF 37), Welimann otra (UF 70), Hiltibald dos (UF 185 y 196), Theotricus otra (UF 263).

48 UF 229, 241, 242 y 243. Anteriormente mantenía los dos términos: UF 144, 172, 181, 182, 183 , 192, 200, 201, 202, 203, 204, 206, 207, 209, 210 y 213. 
ESCRIBIR EL ESPACIO ENTRE LA AUCTORITAS, LA LENGUA HABLADA Y EL RÉGIMEN AGRARIO: CAMPUS EN LOS FONDOS DOCUMENTALES DE WISSEMBOURG, LORSCH Y FULDA...

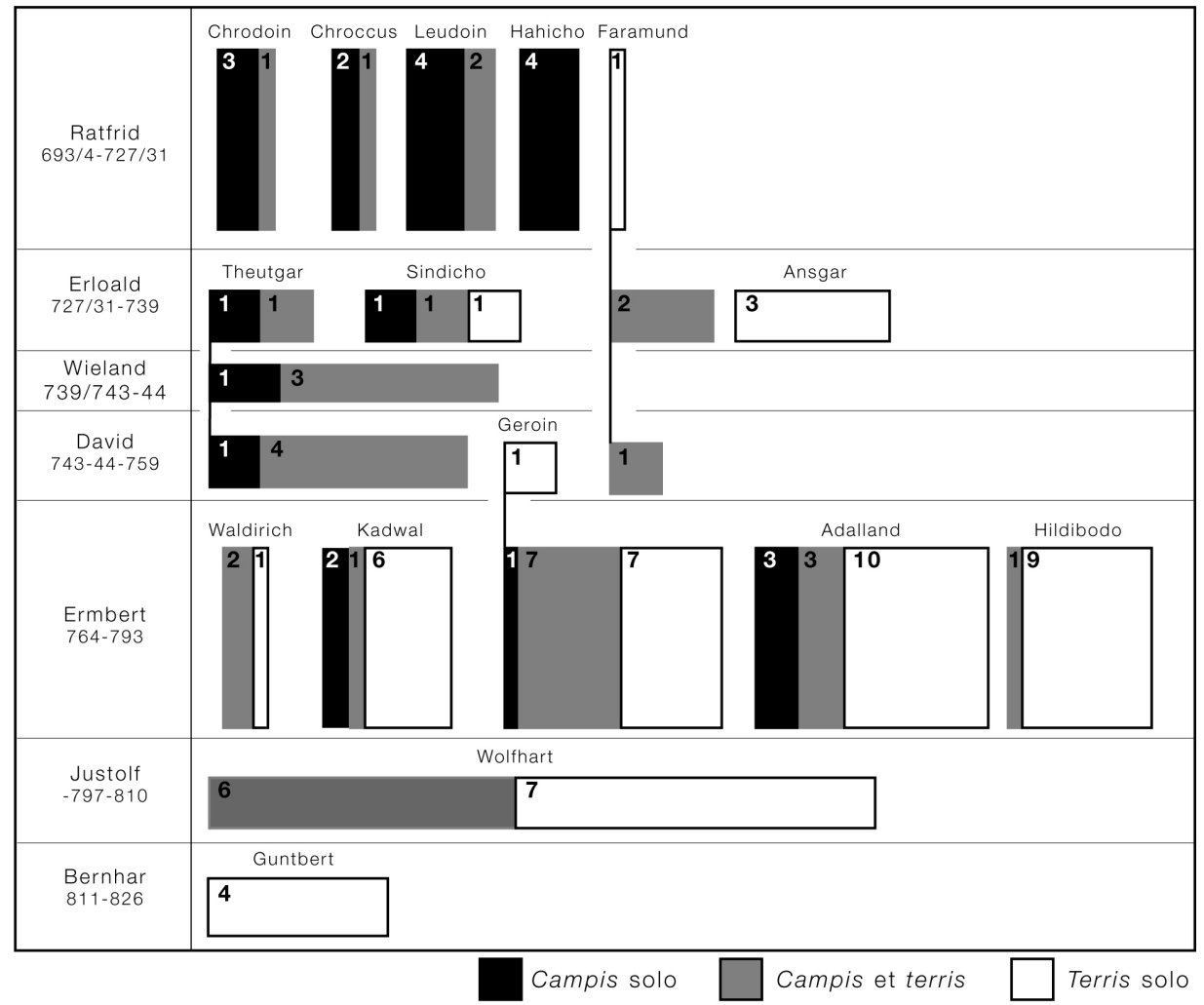

Figura 2. Campis y terris en las fórmulas de pertenencia de los escribas de Wissembourg, ordenadas por abadiatos ${ }^{49}$.

Pero basta que el más veterano se retire para que Hracholf recupere el uso sistemático de ambas palabras y sea seguido por los demás escribas de Fulda al menos hasta mediados del siglo $\mathrm{IX}^{50}$.

Hay de todos modos en Fulda una tímida innovación que no carece de interés. Dos actas copiadas sin suscripción del escriba, redactadas entre 791 y 794 la primera, y entre 780 y 802 la segunda, proponen una enumeración simplificada concebida en torno a la oposición entre campus y silva ${ }^{51}$. La primera sitúa esta oposición encabezando una

49 Las cifras indican el número de documentos que contiene alguna de las tres opciones. La superficie de cada casilla es proporcional al número de documentos; la forma es más o menos alargada verticalmente en función de la duración de cada abadiato. Solo se han tenido en cuenta los escribas que emplean estas fórmulas en al menos tres documentos.

50 UF $233,238,239,244,262,269,276,277,280,526$ y 527. Sobre ambos escribas, SANdmanN, Mechthild. «Wirkungsbereiche fuldischer Mönche». En Schmid, Karl (ed.). Die Klostergemeinschaft von Fulda im früheren Mittelalter. 2.2. Untersuchungen. München: Fink, 1978, pp. 693-792 (pp. 705-707).

${ }_{51}$ UF 211 y 404. 
ESCRIBIR EL ESPACIO ENTRE LA AUCTORITAS, LA LENGUA HABLADA Y EL RÉGIMEN AGRARIO: CAMPUS EN LOS FONDOS DOCUMENTALES DE WISSEMBOURG, LORSCH Y FULDA... JUAN JOSÉ LARREA

enumeración muy simple -integrum, id est silvam, campum, prata, pascua, aedificia, alia confinia [siguen ganado y esclavos]-. La segunda es aún más austera: cum campo et silva et prato et pascuis. No llegarán a ser la regla del escritorio, pero el empleo de campus/silva como manera de englobar todo el espacio susceptible de ser explotado est visible tanto en enumeraciones de la primera mitad del siglo $\mathrm{IX}^{52}$ como en el dispositivo de algunos documentos. Así, una donación efectuada en 815 comprende duas hobas [dos explotaciones agrarias] unam in campis et alteram in siluis ${ }^{53}$.

En suma, las manipulaciones de las fórmulas de pertenencia muestran, además de la coherencia en el tiempo de las prácticas de cada scriptorium, una percepción de campus y terra no como estrictamente sinónimos, sino como facetas de una misma realidad que son redundantes en tanto en cuanto la descripción se mantiene en su nivel de detalle más bajo. Otra cosa es cuando pasamos a los dispositivos.

\section{CAMPUS EN LOS Dispositivos}

Como cabía esperar, las menciones más tempranas de campus en los dispositivos de los documentos provienen del cartulario de Wissembourg. Son nueve en otras tantas actas de entre 712 y 783 , sobre un total de 143 para este mismo tramo cronológico ${ }^{54}$. Entre ellas encontramos campus utilizado en oposición al recinto habitado, de modo semejante a lo que veíamos en el Vocabularius St. Galli ${ }^{55}$. Pero es más interesante comprobar que, como dejaban prever las fórmulas de Marculfo, campus aparece en dispositivos especialmente atentos al detalle en la descripción, lo que nos permite distinguir tres rasgos mayores de los campi del escritorio alsaciano.

El primero es que se trata generalmente de parcelas rectangulares, a veces amojonadas y de dimensiones variables. Cuando se precisa la superficie, encontramos campi de diez, doce y veinte jornales, es decir en torno a tres, tres y media y seis hectáreas ${ }^{56}$. A título de mera referencia, los historiadores del medio rural han considerado tradicionalmente que treinta jornales o diez hectáreas vienen a ser la superficie apropiada para el sostén de un grupo familiar. En dos ocasiones el escriba sólo ha registrado la medida de un lado de la parcela: un campus con un linde de dos pértigas y dos pies, es decir unos siete metros, y otro con un lado de más de sesenta pértigas que deja entrever una pieza estrecha y alargada.

El segundo rasgo tiene que ver con la posesión, pues tanto los campi objeto de los documentos como aquellos que figuran en calidad de colindantes son bloques

52 CDF 312, 315 y 519.

$53 \mathrm{CDF} 310$.

54 TW 7, 108, 186, 190, 230, 235, 244, 262 y 263.

55 De terra araturia iurnales XX et areale I cum casis et casalis et quicqud supra ipsa areale stabilita est. Ab uno latus tenit Sigibaldus, ab alio latus pergit in campo, ab uno fronte tenit Milone et ab alio uiro fronte tenit ipse uendeture (TW 190).

56 Como referencia para las equivalencias aproximadas de las unidades de medida carolingias, WEIDINGER, Ulrich. Untersuchungen zur Wirtschaftsstruktur des Klosters Fulda in der Karolingerzeit. Stuttgart: Hiersemann, 1991, pp. 88-92. 
ESCRIBIR EL ESPACIO ENTRE LA AUCTORITAS, LA LENGUA HABLADA Y EL RÉGIMEN AGRARIO: CAMPUS EN LOS FONDOS DOCUMENTALES DE WISSEMBOURG, LORSCH Y FULDA...

de un solo propietario. Esto no significa que no haya terrenos en copropiedad. De hecho, encontramos piezas limítrofes que pertenecen a grupos de consortes o de coherederos, pero en tales casos el escriba se limita a identificar a los dueńos sin etiquetar los terrenos como campi. Desgraciadamente, las menciones son tan escasas que no podemos extraer de ellas conclusiones de alcance general. De hecho, a falta de número suficiente de casos concretos que permitan resolver, algunas menciones quedan atrapadas en la ambigüedad:

hoc est de terra culturali xx iurnales in campum unum iuntos, et est terminata: ab uno latere habet Suaidemundus et ab alio latere habet Ratuuino et ab uno fronte peruenit in Saluxsia (TW 7).

En este caso ¿campus designa el todo o la parte? ¿Se trata de una pieza situada dentro de un campus compartido por varios cultivadores cuyas parcelas parecen alinearse perpendicularmente al río? ¿ O el que una superficie compacta y de cierta dimensión pueda delimitarse con precisión dentro de un sector de tierra arable lleva a denominarla campus? Sospechamos en realidad que ambas opciones son compatibles, pues la noción de campus, tal y como se percibe en estos documentos, conjuga el plano de la posesión con el de la organización del espacio.

La tercera característica de los campi según aparecen en el cartulario de Wissembourg consiste en encontrarse regularmente en sectores que combinan la explotación agrícola con la del bosque. Naturalmente, no se trata de volver a la venerable imagen del combate plurisecular con la foresta primitiva. El bosque era más bien, por decirlo rápidamente, el espacio del monte bajo, la explotación de las hojas para forraje, los pastos, la montanera y los cultivos temporales. Es decir, un espacio explotado no menos intensamente que los campi, pero en el que los útiles, los gestos técnicos y el calendario de faenas son distintos. Lo que sobre todo queremos destacar es que la relación entre campi y silva no es solo de proximidad. Más bien al contrario, se trata de un vínculo orgánico, tanto cuando el acceso a la silva aparece vinculada a la posesión del campus...

de terra arabili iurnales $\mathrm{x}$ in campo uno simul cum marca de silua, seo et in aliis locis duas stirpis ad stirpandum cum pascuis aquis aquarumue decursibus. Unde accipe ad te precio [...] ut ab hac die suprascripta terre in tribus illis locis in suprascripta marcha (TW 186).

... como cuando una y otro se presentan en asociación:

Et habet iste campus] in lo[n]go perticas legitimas ad brachio mensuratas tisas duas et duas pedes ad manus mensuratas. De ipsa silua sua portione perticas nonaginta et una. Et in ipsa marca in alio loco silua (TW 244).

Tanto portio de silua como marca de silua se refieren a la participación en un derecho colectivo de explotación del bosque. Ahora bien, no aluden a un posible derecho de acceso a espacios incultos del que disfruten todos los posesores de una determinada localidad, de manera similar a los comunales de las comunidades de aldea clásicas ${ }^{57}$, sino

57 Cf. Doll, Traditiones Wizenburgenses, p. 390. 
ESCRIBIR EL ESPACIO ENTRE LA AUCTORITAS, LA LENGUA HABLADA Y EL RÉGIMEN AGRARIO: CAMPUS EN LOS FONDOS DOCUMENTALES DE WISSEMBOURG, LORSCH Y FULDA... JUAN JOSÉ LARREA

que conciernen solo a las franjas de espacios incultos que rodean cada bloque de cultivos y que pivotan sobre la posesión de parcelas concretas en esos sectores. Volveremos sobre esto un poco más adelante.

Si consideramos ahora nuestras observaciones previas sobre el uso de campus en las fórmulas de pertenencia del escritorio de Wissembourg, descubrimos una correlación interesante. Varios de los escribas de la primera fase mostrada por el gráfico de la figura 2 emplean campus tanto en las enumeraciones como en los dispositivos que acabamos de examinar $^{58}$. En cambio, los escribas que registran lo mayor de la expansión patrimonial bajo los carolingios suprimen campus de ambas partes ${ }^{59}$. En nuestra opinión, es un síntoma de coherencia formal en su práctica, pero no hay que ver en este cambio una ruptura. De hecho, en la fraseología de los más antiguos como en las de los más recientes, la sustancia transferida es siempre la terra aratoria, preséntese esta de manera concreta como un campus -de terra aratoria campum I (TW 108)-, o como una suma de jornales -de terra araturia iurnales XXI (TW 83)-, por ejemplo. Nos encontramos así con el ejercicio de una opción entre dos facetas de una misma realidad cuyo criterio apunta hacia las nociones no opuestas pero sí distinguibles del trabajo y la posesión.

Sobre todo esto, los textos de Lorsch arrojan una luz diferente y complementaria. El Codex Laureshamensis registra, en efecto, centenares de transmisiones de tierra arable según la fórmula consistente en dar la superficie en jornales: de terra araturia III iurnales ${ }^{60}$. Estas expresiones, incluso cuando se trata de pequeñas superficies, engloban a menudo varias piezas repartidas en sectores diferentes de un término, tal y como muestran algunos documentos especialmente detallados ${ }^{61}$ :

de terra araturia XXvIII iurnales in tribus locis sitos (dentro del término de Grenzhof, CL 662).

in Dossenheim II iurnales, et dimidium in duobus locis (CL 401).

uobis uendi[di]sse, de terra arabili iurnales IIIIor in Basinsheimmer marcha, et accepi a uobis pretio [...] et memoratam terram uestro misso presentialiter tradidi possidendum, et loca singula ubi iacebant assignaui (CL 247).

Recordemos en este sentido el alto grado de fragmentación de la posesión fundiaria en la región, donde el número de cultivadores en cada localidad puede llegar a algunas decenas $^{62}$.

58 Es el caso de Chrodoin, Leudoin, Hahicho o Theutgar: TW 244, 262, 235,7, respectivamente.

59 Adalland, Geroin, Kadwal o Hildibodo.

60 CL 303.

61 Además de los documentos citados en el texto, CL 700 (dos jornales en dos lugares), 859 (dos jornales escasos en dos lugares), 914 (dos jornales y medio en dos lugares).

62 Schwind, «Struktur»; Gockel, Michael. Karolingische Königshöfe am Mittelrhein. Göttingen: Vandenhoeck \& Ruprecht, 1970, pp. 222 y ss.; SPRANDEL, Rolf. «Die frühmittelalterliche Grundbesitzverteilung und Gerichtsordnung im fränkischen und alemannischen Raum». En Quarthal, Franz (ed.). Alemannien und Ostfranken im Frühmittelalter. Bühl-Baden: Konkordia, 1984, pp. 47-59; WickHam, Chris. Framing the Early Middle Ages. Europe and the Mediterranean, 400-800. Oxford: Oxford University Press, 2005, p. 394; Kohl, Thomas. "Gemeinde vor der Gemeinde? Dienheim in karolingischer Zeit». En Greule, Albercht y Meier, Jörg (eds.). Die ländliche Gemeinde im Spätmittelalter. Berlin: Weidler, 2005, pp. 185-204. 
ESCRIBIR EL ESPACIO ENTRE LA AUCTORITAS, LA LENGUA HABLADA Y EL RÉGIMEN AGRARIO: CAMPUS EN LOS FONDOS DOCUMENTALES DE WISSEMBOURG, LORSCH Y FULDA... JUAN JOSÉ LARREA

La presencia de campus en los dispositivos de los documentos de Lorsch se limita a cuatro menciones entre 769 y 790 , y esto para un volumen de actas unas diez veces mayor que el de Wissembourg. Dicho lo cual, también para los escribas de Lorsch campus designa una parcela de tierra arable cuya superficie, lindes o vinculación con vacantes pueden ser señalados ${ }^{63}$. El ejemplo más elocuente proviene de una donación localizada en Mannheim en 770:

campum I de terra araturia tenentem iurnales $\mathrm{x}$, et terram incultam ad ipsum campum pertinentem (CL 561).

A pesar de la extrema penuria de menciones, los fondos de Lorsch proporcionan elementos de explicación para entender justamente esta escasez. Esto es así porque en las secciones de los pagi de Oberrheingau y Lobdengau, y para el tiempo de los tres primeros abades (765-804), el Codex Laureshamensis atesora el conjunto de documentos más voluminoso, compacto y rico en detalles sobre el paisaje agrícola de las primeras generaciones carolingias ${ }^{64}$. Este dossier de 500 actas cuenta con 213 menciones de tierras dadas o vendidas a Lorsch, de las que 162 no alcanzan los once jornales, como puede verse en el gráfico de la figura 3. Claro está que este gráfico es antes que nada el reflejo de las estrategias de los tradentes de la región en relación a la abadía, es decir que hay que ver en él la traducción fundiaria de un tejido de clientela y alianza que los escribas deben registrar acta a acta. En ningún caso puede leerse como una muestra estadística de las explotaciones de toda la región o de un término concreto. La proporción de superficies minúsculas puede perfectamente estar sobrerrepresentada con respecto a la fragmentación y a la circulación de tales parcelas entre el conjunto de posesores del país. Pero lo que nos interesa aquí es subrayar la plasticidad de las estructuras fundiarias.

A esta pulverización de las donaciones se adecua muy bien la fórmula « $\mathrm{X}$ jornales de tierra arable», por ser flexible, eficaz y económica con independencia de que pueda haber campi en la organización del terrazgo. Además, hay un umbral de superficie por encima del cual la descripción de la tierra arable cambia en la práctica del scriptorium: por mucho que Lorsch reciba a veces mansos con una dotación fundiaria irrisoria, se observa en el gráfico que las superficies de tierra arable circulan aisladamente cuando son modestas, pero que tienden a aparecer asociadas a los mansos en cuanto alcanzan un cierto orden de magnitud. La explicación está sin duda en que todas las explotaciones agrícolas de la zona se organizan en torno a los mansos, cada uno de los cuales está compuesto del recinto edificado -el manso en sentido estricto- $\mathrm{y}$ del conjunto de cultivos y derechos de uso que dependen de la zona de habitación. Aunque los ajustes entre la fuerza de trabajo disponible en los mansos y la tierra labrada sean constantes, no parece razonable dislocar bloques fundiarios que superen la mitad de la dotación de un manso.

63 En Kerzenheim (Donnersbergkreis), los monjes reciben la mitad de un campo cuyo emplazamiento muestra su carácter de parcela concreta: et I uineam, in Quirnheim, siue in Rodenbach, et I dimidium campum eidem uinee coniunctum (CL 838). Las otras dos menciones se refieren a otros tantos campi sin mayor indicación que su percepción como unidades (campum unum de terra arabili (CL 1004), I campum (CL 1367). Este último proviene de una sección del Codex cuyas copias están muy abreviadas.

${ }^{64}$ Larrea, «Manse», pp. 59 y ss. 
ESCRIBIR EL ESPACIO ENTRE LA AUCTORITAS, LA LENGUA HABLADA Y EL RÉGIMEN AGRARIO: CAMPUS EN LOS FONDOS DOCUMENTALES DE WISSEMBOURG, LORSCH Y FULDA... JUAN JOSÉ LARREA

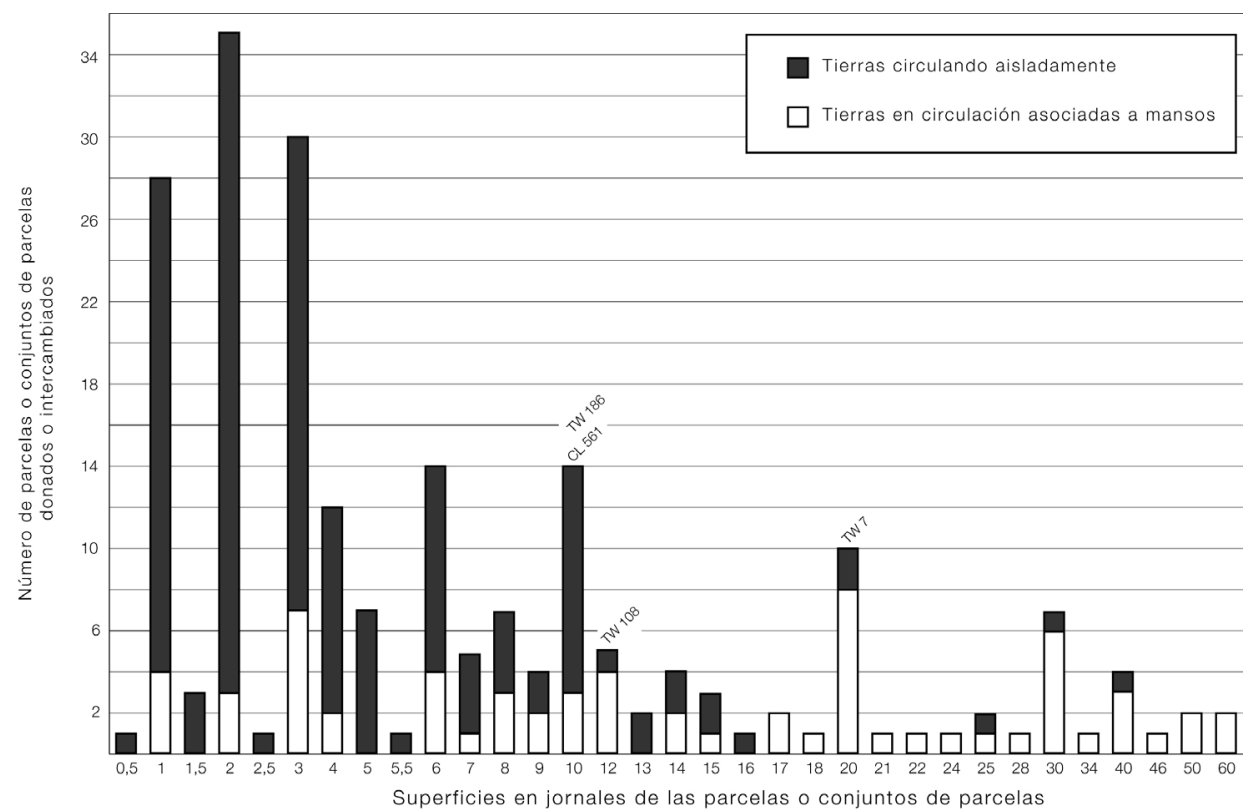

Figura 3. Distribución por superficies de las parcelas o grupos de parcelas cuya superficie es precisada en las secciones de Oberrheingau y Lobdengau del Codex Laureshamensis $(755-804)^{65}$.

Volvamos ahora a los campi. Aunque las menciones son escasas y esta observación deba ser contemplada con precaución, las superficies de campi registradas en Lorsch y Wissembourg se encuentran justamente en torno al umbral crítico de entre doce y dieciséis jornales (figura 3). Por debajo de este umbral, la polvareda de pequeñas piezas se registra eficazmente anotando la superficie total en el conjunto del término. Pero, por encima de este umbral, campus se difumina en el bloque fundiario y humano anejo a los mansos, los cuales proporcionan una referencia suficiente a los actores de las transmisiones. En estas condiciones, campus tiene pocas oportunidades de aparecer en los documentos.

En el tercer fondo de archivo, el de Fulda, los campi también son escasos, pero aquí los criterios son muy otros, al igual que ocurría con las fórmulas de pertenencia. Se diría que han optado por utilizarlo con su significación global de espacio abierto y opuesto al saltus, de un modo que parece más permeable a su uso en el registro culto y más fiel a las colecciones de fórmulas. Así, las también cuatro menciones de campus en los fondos de Fulda no se refieren nunca a parcelas concretas. Cuando los escribas del scriptorium monástico quieren describir parcelas, emplean ager. Es efectivamente lo que aparece en tres documentos: uno registra un agrum rectangular de media hectárea próximo a la iglesia de Thulba (Bad Kissingen), mientras que los otros anotan la donación de algunos agros

65 Identificados por las siglas de los documentos, los campi de Lorsch y Wissembourg se sitúan sobre las columnas correspondientes a sus superficies. 
ESCRIBIR EL ESPACIO ENTRE LA AUCTORITAS, LA LENGUA HABLADA Y EL RÉGIMEN AGRARIO: CAMPUS EN LOS FONDOS DOCUMENTALES DE WISSEMBOURG, LORSCH Y FULDA...

en términos del pagus de Worms ${ }^{66}$. Además de esto, ager puede tener también un sentido genérico referido a la condición de tierra arable de un espacio -tres uirgas in latitudine cum sua longitudine agrorum arabilium ${ }^{67}$, o a los terrenos abiertos accesibles desde una parcela parcialmente enclavada entre lindes:

illam rem quam tradamus alienas partes circumiacent. Hoc est in una parte habet sanctus Mahsmannus et in altera parte habet Adalhart et tertia pars communis est uia et quarta pars exiuit in agrum ${ }^{68}$.

Ager funciona aquí en oposición a espacios cercados o susceptibles de serlo, puesto que el pasaje se refiere sin duda a recintos edificados y que la misma fórmula se emplea a continuación para indicar el acceso del que disponen otras viñas parcialmente enclavadas.

¿Qué hay entonces de campus? Los escribas de Fulda hacen deslizar el sentido de campus hacia una connotación genérica, integrándolo a la vez en juegos de oposiciones. Campi tiene en un caso el sentido de tierras arables -trado X. iugera in campis ${ }^{69}-$, pero en los demás funciona por contraste con otros tipos de espacio. Tenemos así una fórmula análoga a la que acabamos de examinar a propósito de ager:

unam uineam in uilla Teinenheim quae habet in uno latere uineam regis et in alio latere sancti saluatoris et in tertio sancti Bonifatii in quarto latere campum uacuum (CDF 250).

En los demás casos, se opone a silva, lo que es por otro lado coherente con el tratamiento de las fórmulas de pertenencia en este escritorio. Conocemos ya la expresión duas hobas unam in campis et alteram in siluis ${ }^{70}$. Pero quizá la cuarta mención es la más sugestiva, porque introduce un componente topográfico que parece depender más del sistema general de representación que de la realidad visible:

xxx iugera. $\mathrm{xv}$ iam stirpata et ad arandum in planitiemque campi parata et alia $\mathrm{xv}$ adhuc siluis occupata (CDF 352).

En esta donación de un terreno en Geldersheim (Schweinfurt), se ve un proceso de roturación inacabado para el que no es difícil encontrar paralelos ${ }^{71}$. Ahora bien, no solo el término de Geldersheim no tiene cuestas, sino que la planities campi es una alusión al resultado del desbrozamiento en curso, independientemente de la topografía concreta de los campi y la silva. Más que en relación a la realidad local, parece que es a la luz de la asociación entre llano y campus en los textos de la auctoritas como la connotación topográfica recupera su sentido ${ }^{72}$.

66 CDF 416, 198 y 216.

67 CDF 404. Una formulación análoga, pero mas ambigua: CDF 515.

68 CDF 228. Un caso semejante: CDF 198.

69 CDF 327. El ingerum equivale al jornal (supra n. 55).

70 CDF 310.

71 Por ejemplo, CL 393 y 491.

72 Sobre la escritura en tanto que «vector de intercambios simbólicos», Morsel, Joseph. «Ce qu'écrire veut dire au Moyen Âge... Observations préliminaires à une étude de la scripturalité médiévale». Memini. Travaux et Documents de la Société des Études Médiévales du Québec, 2000, vol. 4, pp. 3-43. 
ESCRIBIR EL ESPACIO ENTRE LA AUCTORITAS, LA LENGUA HABLADA Y EL RÉGIMEN AGRARIO: CAMPUS EN LOS FONDOS DOCUMENTALES DE WISSEMBOURG, LORSCH Y FULDA... JUAN JOSÉ LARREA

CAMPUS EN LA ARTICULACiÓN ENTRE LOS CULTIVOS Y LOS RECURSOS DEL ESPACIO INCULTO

Tanto en los dispositivos de Wissembourg como en los de Lorsch hemos detectado usos de campus en los que este aparece asociado al derecho de acceso a un sector del espacio inculto circundante. En realidad, la proyección de la posesión de parcelas de cereal o de viña en forma de derecho preferente de acceso a los vacantes próximos y/o de apropiación por roturación de los mismos forma parte de la panoplia de mecanismos de apropiación del yermo en el régimen agrario de la región. Este derecho preferente se materializa de forma flexible, de modo que puede consistir tanto en la participación en la explotación colectiva de los pastos, del follaje, de la leńa y de la madera, como en la roturación y apropiación de algunos terrenos, sin duda vinculados a cultivos temporales. Habiéndose tratado generalmente desde el punto de vista de la historia del Derecho o de la historia institucional ${ }^{73}$, es una práctica muy interesante porque evidencia la actividad de pequeños colectivos de cultivadores organizando la explotación del inculto por sectores, en una época de desplazamientos cíclicos de los cultivos y del hábitat: recordemos que los protagonistas de nuestros documentos son los nietos, cuando no los hijos, de los últimos enterrados en las necrópolis de plein champ.

Las formulaciones más claras provienen del escritorio de Lorsch, que identifica la dependencia del terreno apropiado por roturación a través de expresiones explícitas del tipo ad ipsam uineam pertinentem; ad ipsum campum pertinentem ${ }^{74}$. En el Codex Traditionum de Wissembourg se entrevén dos modalidades. La primera, en Alsacia, se asemeja a las de Lorsch, de modo que el acceso al sector circundante del inculto pivota sobre la posesión de una parcela ${ }^{75}$. La segunda, propia del Sarre, asocia estrechamente una parcela concreta y un espacio de bosque según la fórmula campo et silua insimul tenente, pero la silva aquí parece estar tan perfectamente delimitada como el campus $^{76}$.

El hecho de que, con ser escasísimo en el conjunto documental fuera de las fórmulas, campus aparezca tanto en Wissembourg como en Lorsch asociado a esta práctica, siendo así que parece designar comúnmente parcelas compactas de en torno a diez o

73 Ganahl, Karl Hans. «Die Mark in den älteren St. Galler Urkunden (1)». Zeitschrift der Savigny-Stiftung für Rechtsgeschichte: Germanistische Abteilung, 1940, vol. 60, pp. 197-251 (pp. 217-218 y 226), dentro del viejo debate sobre la comunidad de marca y en buena medida en la línea de O. Gierke y G. L. Maurer; NJeussychin, Aleksandr I. Die Entstehung der abhängigen Bauernschaft als Klasse der frühfeudalen Gesellschaft in Westeuropa vom 6. bis 8. Jahrhundert. Berlin: Akademie-Verlag, 1961, pp. 140-141, vinculándolo al paso de la comunidad de clan (Sippengemeinde) al feudalismo; LüTge, Friedrich. Die Agrarverfassung des frühen Mittelalters im mitteldeutschen Raum vornehmlich in der Karolingerzeit. Jena: Gustav Fischer, 1937, pp. 312-313. El punto de vista de los historiadores del Derecho en JäGER, Helmut y Sorhagen, Ingeborg. «Bifang». En Hoops, Johannes (ed.). Reallexikon der Germanischen Altertumskunde. Berlin-New York: De Gruyter, 1976.

74 quartam partem de uinea I, et unum proprisum ad ipsam uineam pertinentem (CL 544); campum I de terra araturia tenentem iurnales $X$, et terram incultam ad ipsum campum pertinentem (CL 561). Terra inculta como equivalente de tierra a roturar: CL 3704a=3057. Otros ejemplos, CL 394, 402, 776, 1812; vinculados a viñas, CL 243, 310, 291, 535, 795, 859, 1267).

75 TW 186.

76 TW 244, 262 у 263. 
ESCRIBIR EL ESPACIO ENTRE LA AUCTORITAS, LA LENGUA HABLADA Y EL RÉGIMEN AGRARIO: CAMPUS EN LOS FONDOS DOCUMENTALES DE WISSEMBOURG, LORSCH Y FULDA... JUAN JOSÉ LARREA

quince jornales, sugiere que no bastaba con disponer de alguna de las piezas minúsculas que proliferan en la documentación, sino que había que asegurar una actividad relativamente estable y consistente como cultivador en un sector concreto para gozar del derecho preferente de acceso al inculto circundante.

$\mathrm{Si}$ bien las correlaciones entre términos que examinamos en la primera parte del artículo parecían apuntar al uso de agerlacker para designar una parcela concreta, esto solo hubiera atendido a cuestiones de orden topográfico o morfológico. En realidad, son las nociones de trabajo y posesión las que reordenan cada juego de oposiciones, siendo así que campus se aleja de la noción de trabajo desde la exégesis a la producción de documentos, pasando por la lengua vernácula -mientras que la terra, ya de entrada, se transfiere a través de su medida en jornadas de trabajo-. En la práctica agraria que estamos viendo, es la posesión y posiblemente la calidad de la misma la que confiere el derecho sobre un sector del yermo.

Dicho esto, no es menos interesante observar por qué una práctica agraria con toda seguridad muy extendida no tiene un reflejo proporcionado ni en la terminología ni en general en el conjunto de descripciones del paisaje de la región. De entrada recordemos que no encontraremos campus en este contexto en los fondos de Fulda. Lo cual no significa ni mucho menos que sus actas ignoren este derecho de acceso a los vacantes organizado por sectores. Tan es así que los documentos de Fulda nos proporcionan una de las palabras vernáculas que se utilizaban para referirse a los vacantes apropiados dependientes de parcelas, anariutu (literalmente, «terreno roturado adyacente») ${ }^{77}$, cuando no utilizaban la expresión latina in circuitu en relación a la roturación vinculada a una pieza $^{78}$. Ahora bien, ya hemos visto que la connotación con que usan campus sus escribas lo hace incompatible con estas descripciones.

Hemos comprobado también que la economía de las descripciones y el contenido mismo de muchas donaciones arrinconan, por así decir, el empleo de campus, a lo que aun podemos ańadir otro factor. El hecho de que una parte de los documentos del Codex Laureshamensis estén copiados dos veces, una en forma de diploma en primera persona y otra en forma de noticia en tercera persona, permite a veces observar partes del dispositivo original que, habiéndose suprimido de una de las dos copias, se han mantenido en la otra. Gracias a esto, podemos estar seguros de que la alusión a la dependencia de un terreno vacante con respecto a una parcela ha sido eliminada por los copistas un número indeterminado e indeterminable de veces ${ }^{79}$. Son aquí las condiciones de preservación de las fuentes las que han de ser tenidas en cuenta junto con los usos terminológicos de los scriptoria. En fin, piénsese que, desde el punto de vista del adquiriente, la transmisión de la parcela bastaba sin duda para asegurar su derecho sobre los vacantes del sector, lo que ya en el momento de la redacción podía hacer considerar superfluo consignar este vínculo.

77 XIII ingera cum anariutu (CDF 469): sobre el término, LüTGE, Agrarverfassung, pp. 307 y 312.

78 Duo ingera excultae terrae et unam capturam in circuitu illorum iugerum sitam (CDF 377).

79 Así, XX iurnales de terra aratoria et pratum ad V carradas et siluam, según se lee en la copia en forma de donación, se convierte en XX iurnales de terra, et de prato ad V carradas feni, et siluam ad ipsam terram pertinentem en la copia en forma de noticia (CL 3163=3703c). 
ESCRIBIR EL ESPACIO ENTRE LA AUCTORITAS, LA LENGUA HABLADA Y EL RÉGIMEN AGRARIO: CAMPUS EN LOS FONDOS DOCUMENTALES DE WISSEMBOURG, LORSCH Y FULDA... JUAN JOSÉ LARREA

UNA REFERENCIA MERIDIONAL

Ampliar el marco territorial de nuestro estudio exigiría aplicar el mismo método a otros fondos documentales, lo que naturalmente está aquí fuera de lugar. El objeto de este último apartado no es otro que apuntar ciertos comportamientos lingüísticos y terminológicos observables en las regiones limítrofes de Alamania y Baviera de cara a identificar algunos elementos, por decir de algún modo, de transición hacia otros usos de escritura. En cualquier caso, la comparación siempre tiene la virtud de hacer más nítidas las especificidades y las semejanzas.

Debido a la geografía bilingüe de su ámbito patrimonial, los fondos de San Gall nos ponen ante una situación muy distinta de la que hemos venido viendo, en el sentido de que campus no siempre es un término ajeno a la realidad de la lengua hablada ${ }^{80}$. En efecto, si nos fijamos en los territorios de lengua alemánica, comprobamos que el tratamiento de campus insiste en algunas de las variantes que ya hemos identificado en Fulda, en particular su uso con connotaciones genéricas. Campus designa en estos documentos las tierras arables -unum iornalem de campo arativo- y se opone a silva ${ }^{81}$. Encontramos incluso la pareja campatum et silvaticum para distinguir los espacios cultivados de los derechos de acceso al bosque ${ }^{82}$. Es, sin duda, esta acepción de territorio explotado y organizado por un grupo de habitantes la que hace inteligible campus en tanto que escenario público de una ceremonia de donación: Actum in campo, vbi dicitur Paumcartun publici $i^{83}$.

Ahora bien, en la zona latinófona de Recia septentrional, en torno a Feldkirch (Vorarlberg, Austria), San Gall se hizo con un conjunto de propiedades cuya transmisión al monasterio fue acompañada de la entrega de documentos anteriores que justificaban el derecho de los tradentes sobre los bienes donados. Redactadas por escribas locales, estas actas de venta y donación entre laicos forman un «paisaje documental» singular que ha llamado desde hace tiempo la atención de los especialistas de la diplomática, el escrito y la lengua ${ }^{84}$.

Consideraremos aquí los diecisiete documentos relativos a campi y agri de los llamados «archivos de Folcwin», compuestos entre 817 y 821 por un importante escriba del país, llamado Andreas, y por sus alumnos ${ }^{85}$. Se trata de parcelas de unos dos o tres modios, localizadas dentro de bloques de cultivos ${ }^{86}$. Estas actas, escritas o supervisadas por Andreas, emplean agrum para designar estas piezas en quince ocasiones ${ }^{87}$ y campus

80 Sobre la producción de documentos en este contexto de interacción entre niveles de uso distintos de la lengua latina, BANniard, Michel. "'Dues pezze de terra”. Remarques sur le diasystème communicationnel d’une charte écrite à Salerne en 837». Reflexos, vol. 3, 2014 [http://revues.univ-tlse2.fr/reflexos/index. php?id=509].

81 ChSG 96

82 Wartmann, Hermann. Urkundenbuch der Abtei Sanct Gallen I (700-840). Zürich: Höhr, 1863, n. ${ }^{\circ} 410$.

83 ChSG 72.

84 Erhart, Peter y Kleindinst, Julia. Urkundenlandschaft Rätien. Wien: VÖAW, 2004.

85 Ibíd., pp. 60-61.

86 El modio equivale a unos 1.200 metros cuadrados.

87 ChSG 225, 239, 248, 261, 262, 263, 264, 265, 267, 271, 272, 273, 278, 279 y 304 . NB: la numeración es diferente en ERHART y KLEINDINST, Urkundenlandschaft. 
ESCRIBIR EL ESPACIO ENTRE LA AUCTORITAS, LA LENGUA HABLADA Y EL RÉGIMEN AGRARIO: 74 CAMPUS EN LOS FONDOS DOCUMENTALES DE WISSEMBOURG, LORSCH Y FULDA...

en solo dos, con la particularidad de que no escriben campum, sino $c a m p u^{88}$. El matiz es significativo. Por mucho que la pérdida de consonantes finales sea uno de los efectos característicos de la influencia del latín hablado sobre el escrito en la zona ${ }^{89}$ y que otros escribas locales escriban agru en lugar de agrum $^{90}$, Andreas y sus alumnos no yerran nunca en la declinación de ager. Ahora bien, en cuanto reemplazan ager por campus, y a pesar de tratarse del mismo formulario de base, dejan de lado la declinación correcta y escriben campu. Esto no solo sugiere que campu era el nombre dado a estas parcelas en la lengua hablada -la palabra existe en todos los dialectos romanches-, sino que era percibido, quizá por esta misma razón, como poco adecuada para el registro escrito.

Terminaremos en Baviera, en cuyos fondos campus es tan escaso fuera de las fórmulas de pertenencia como en los del Medio Rin. Thomas Kohl ha mostrado que campus tiene en esta región un sentido englobante similar al que acabamos de ver en los documentos provenientes de zonas germanófonas de San Gall: o bien designa agregados de parcelas localizadas con precisión, o bien tiene el sentido de conjunto de tierras arables dependiente de una villa o vicus ${ }^{91}$. No hay en efecto ningún campus concreto que sea objeto de una donación o transacción en los fondos de Freising, Ratisbona-San Emerano o Mondsee.

El interés de campus en los documentos bávaros está en que hacen reaparecer un par de ideas que recorren este artículo desde su primer apartado. La primera se refiere al trasfondo de las categorías bíblicas de representación del espacio, que volvemos a encontrar aquí. Es el caso de la expresión ya vista en Fulda de planitie camporum en relación en este caso al término de Atting (Straubig-Bogen) que es particularmente llano:

iugera terrae arabilis tria ad sanctum dei martyrem Emmerammum, iacentia in planitie camporum iuxta uicum qui dicitur Attinga92.

Del mismo modo, la oposición campestrialmontana referida a la localidad montañesa de Innichen (Bolzano) se hace eco de numerosos pasajes del Antiguo Testamento ${ }^{93}$ :

totum atque integrum campestria seu et montana, pascuas, venationes, umecta seu frutecta omnia ad eadem pertinentia locum ${ }^{94}$.

La segunda idea concierne la relación entre la necesidad de precisión y la elección de determinada palabra, lo que se hace particularmente patente en los fondos del monasterio austriaco de Mondsee. En los 135 documentos de entre 736-748 y 854 transmitidos por

88 ChSG 256 y 266.

89 ERhart y KLEINDinst, Urkundenlandschaft, pp. 70-73.

90 ChSG 189.

91 KoнL, Thomas. Lokale Gesellschaften. Formen der Gemeinschaft in Bayern vom 8. bis zum 10. Jahrhundert. Ostfildern: Thorbecke, 2010, pp. 343-344.

92 Widemann, Josef. Die Traditionen des Hochstifts Regensburg und des Klosters St. Emmeram. München: Beck, 1943, n. ${ }^{\circ} 90$.

93 Josué 10:41, 11:16, 9:1; 12:8; Génesis 14:6; Deuteronomio 1:7, 11:11; Jueces 1:9; Jeremías 17:26, 32:44, 33:13; Abdías 1:19.

94 Bitterauf, Theodor. Die Traditionen des Hochstifts Freising. I. (744-926). München: Rieger, 1905, n. 34 . 
ESCRIBIR EL ESPACIO ENTRE LA AUCTORITAS, LA LENGUA HABLADA Y EL RÉGIMEN AGRARIO: CAMPUS EN LOS FONDOS DOCUMENTALES DE WISSEMBOURG, LORSCH Y FULDA... JUAN JOSÉ LARREA

sus cartularios, campus aparece 51 veces en las fórmulas de pertenencia y solamente dos fuera de las mismas. Significativamente, se trata de la única acta de venta de todo el conjunto y de una donación hecha al abad y a su advocatus que deja ver un conflicto previo ${ }^{95}$.

\section{Conclusiones}

Si se quiere admitir una analogía imperfecta, campus en los documentos de Wissembourg, Lorsch y Fulda, y probablemente cualquier término relativo al medio rural en un corpus dado, es un punto en un sistema de coordenadas de tres ejes: el sistema de representaciones difundido por los textos que transmiten la Palabra y la doctrina, la función de cada tipo de documento en el establecimiento de relaciones sociales y la percepción del régimen agrario por los escribas. Ahora bien, no es un punto que resulte de una combinación aleatoria de estos valores, sino que su espacio está delimitado por los criterios y usos de cada scriptorium. Uno de los intereses mayores del estudio de las, por otro lado, poco apasionantes fórmulas de pertenencia es que hacen visibles algunos de estos criterios y su coherencia.

Es interesante observar que representaciones modeladas por la interpretación espiritual del espacio tiñen la escritura de documentos hasta el punto de influir en la descripción de un terreno común y corriente. Pero, quizá más interesante que esto es comprobar que la consistencia de algunos de los hilos que conectan la descripción de los componentes fundiarios de un patrimonio con la lengua vernácula y con la literatura patrística y exegética se debe al juego de relaciones entre dos categorías claves del régimen agrario: el trabajo y la posesión. Es esto lo que explica en buena medida el criterio de los escribas de Lorsch y Wissembourg a la hora de asociar el término campus con la práctica agraria concreta que organiza la explotación del yermo por sectores.

Describir y nombrar un espacio agrario implica seleccionar antes la faceta que se quiere tomar como referencia, lo cual viene condicionado por los marcos de referencia, pero también por las necesidades de conjunto de la producción documental y por la coherencia de los usos terminológicos propios de cada scriptorium. Esto apunta a una precaución metodológica que no debiera obviarse, en el sentido de que las estimaciones de tal o cual práctica agraria basadas en la frecuencia de menciones o en un pretendido valor absoluto de los términos clave no hacen sino prolongar usos ajenos a la lógica interna de las fuentes susceptibles de ser explotadas para la historia rural. Se corre así el riesgo, parafraseando una provocación, en el sentido intelectual del término, de Alain Guerreau, de trabajar como si una planities fuera un llano y un campus fuera un campo.

\section{REFERENCIAS BIBLIOGRÁFICAS}

BANGE, François. «L'ager et la villa: structures du paysage et du peuplement dans la région mâconnaise à la fin du haut Moyen Âge ( $\mathrm{Ix}^{\mathrm{e}}-\mathrm{XI}^{\mathrm{e}}$ siècles)». Annales. Économies, Sociétés, Civilisations, 1984, vol. 39, pp. 529-569.

95 Rath, Gebhard y Reiter, Erich. Das älteste Traditionsbuch des Klosters Mondsee. Linz: Oberösterreichisches Landesarchiv, 1989 , n. ${ }^{\text {os }} 49$ y 8. 
ESCRIBIR EL ESPACIO ENTRE LA AUCTORITAS, LA LENGUA HABLADA Y EL RÉGIMEN AGRARIO: CAMPUS EN LOS FONDOS DOCUMENTALES DE WISSEMBOURG, LORSCH Y FULDA...

BANNiARD, Michel. "'Dues pezze de terra”. Remarques sur le diasystème communicationnel d'une charte écrite à Salerne en 837». Reflexos, vol. 3, 2014 [http://revues.univ-tlse2.fr/reflexos/index.php?id=509].

Bergmann, Rolf. "Althochdeutsche Glossen zu "Bauer"». En Wenskus, Reinhard et al. (eds.). Wort und Begriff "Bauer". Göttingen: 1975, pp. 89-127.

BitTerauf, Theodor. Die Traditionen des Hochstifts Freising. I. (744-926). München: Rieger, 1905.

Borgolte, Michael. Geschichte der Grafschaften Alemanniens in fränkischer Zeit. Sigmaringen: Thorbecke, 1984.

Chastang, Pierre. «La langue, l'écriture et l'histoire. La singulière Catalogne de Michel Zimmermann». Médiévales, 2007, vol. 52, pp. 171-180.

Doll, Anton. Traditiones Wizenburgenses: Die Urkunden des Klosters Weissenburg, 661-864. Darmstadt: Hessische Historische Kommission Darmstadt, 1979.

Dronke, Ernst Friedrich Johann. Codex Diplomaticus Fuldensis. Aalen: 1962 [Kassel, 18501].

Erhart, Peter et al. (eds.). Die Privaturkunden der Karolingerzeit. Dietikon-Zürich: Urs graf, 2009.

Erhart, Peter et al. Chartularium Sangallense. Band I (700-840). St. Gallen: Herausgeber- und Verlagsgemeinschaft Chartularium Sangallense-Thorbecke, 2013.

Erhart, Peter y Kleindinst, Julia. Urkundenlandschaft Rätien. Wien: VÖAW, 2004.

Fischer, Bonifatius (ed.). Vetus Latina. Die reste der altlateinischen Bibel. 2. Genesis. Freiburg: Herder, 1951-1954.

Freise, Eckhard. «Studien zum Einzugsbereich der Klostergemeinschaft von Fulda». En ScHmid, Karl (ed.). Die Klostergemeinschaft von Fulda im früheren Mittelalter. München: Fink, 1978, pp. 1003-1269.

GanaHL, Karl Hans. «Die Mark in den älteren St. Galler Urkunden (1)». Zeitschrift der SavignyStiftung für Rechtsgeschichte: Germanistische Abteilung, 1940, vol. 60, pp. 197-251.

GARCÍA DE CorTÁZAR, José Ángel y AgúNDEz, Leticia. «Memoria y cultura en la documentación del monasterio de Celanova: la respuesta de las "fórmulas inútiles" (años 842-1165)». En Val Valdivieso, M.a Isabel del y Martínez Sopena, Pascual (eds.). Castilla y el mundo feudal: homenaje al profesor Julio Valdeón. Valladolid: Junta de Castilla y León, 2009, pp. 251-267.

GLÖCKNer, Karl. Codex Laureshamensis. Darmstadt: 1929-1936.

Gockel, Michael. Karolingische Königshöfe am Mittelrhein. Göttingen: Vandenhoeck \& Ruprecht, 1970.

Gockel, Michael. «Die Träger von Rodung und Siedlung im Hünfelder Raum in karolingischer Zeit». Hessisches Jahrbuch für Landesgeschichte, 1976, vol. 26, pp. 1-24.

Guerreau, Alain. «Quelques caractères spécifiques de l'espace féodal européen». En BuLst, Neithard et al. (eds.). L'État ou le Roi. Les fondations de la modernité monarchique en France (XIV'-XVIT siècle). Paris: Éditions de la Maison des Sciences de l'Homme, 1996, pp. 85-101.

Jäger, Helmut y Sorhagen, Ingeborg. «Bifang». En Hoops, Johannes (ed.). Reallexikon der Germanischen Altertumskunde. Berlin-New York: De Gruyter, 1976.

Karg-GasterstäDt, Elisabeth y Frings, Theodor. Althochdeutsches Wörterbuch. Berlin: Akademie-Verlag, 1968.

KLeIn, Hans-W. Die Reichenauer Glossen. 1. Einleitung, Text, vollständiger Index und Konkordanzen. München: Hueber, 1968.

Kohl, Thomas. "Gemeinde vor der Gemeinde? Dienheim in karolingischer Zeit». En Greule, Albercht y Meier, Jörg (eds.). Die ländliche Gemeinde im Spätmittelalter. Berlin: Weidler, 2005, pp. 185-204. 
ESCRIBIR EL ESPACIO ENTRE LA AUCTORITAS, LA LENGUA HABLADA Y EL RÉGIMEN AGRARIO: CAMPUS EN LOS FONDOS DOCUMENTALES DE WISSEMBOURG, LORSCH Y FULDA... JUAN JOSÉ LARREA

Koнl, Thomas. Lokale Gesellschaften. Formen der Gemeinschaft in Bayern vom 8. bis zum 10. Jahrhundert. Ostfildern: Thorbecke, 2010.

LADE, Ulrike. Flur und Feld. Volkssprachige Bezeichnungen in den frühmittelalterlichen Leges. Münster: Phil. Fak. Diss., 1987.

LARreA, Juan José. "L'autre visage du manse. Actes de la pratique et structures agraires dans la vallée du Rhin moyen au viII ${ }^{\mathrm{e}}$ siècle». Frühmittelalterliche Studien, 2012, vol. 46, pp. 41-98.

Lauwers, Michel y Ripart, Laurent. "Représentation et gestion de l'espace dans l'Occident médiéval». En Genet, Jean-Philippe (dir.). Rome et l'État moderne européen. Rome: École Française de Rome, 2007, pp. 115-171.

Lohrmann, Dietrich. «Évolution et organisation interne des cartulaires rhénans du Moyen Âge». En Guyotjeannin, Olivier et al. (eds.). Les cartulaires: actes de la table ronde organisée par l'École Nationale des Chartes et le G.D.R. 121 du C.N.R.S. Paris: École des Chartes, 1993, pp. 79-90.

LüTGE, Friedrich. Die Agrarverfassung des frühen Mittelalters im mitteldeutschen Raum vornehmlich in der Karolingerzeit. Jena: Gustav Fischer, 1937.

McKitterick, Rosamond. The Carolingians and the written word. Cambridge: Cambridge University Press, 1989.

Morsel, Joseph. «Ce qu'écrire veut dire au Moyen Âge... Observations préliminaires à une étude de la scripturalité médiévale». Memini. Travaux et Documents de la Société des Études Médiévales du Québec, 2000, vol. 4, pp. 3-43.

NJeussychin, Aleksandr I. Die Entstehung der abhängigen Bauernschaft als Klasse der frühfeudalen Gesellschaft in Westeuropa vom 6. bis 8. Jahrhundert. Berlin: Akademie-Verlag, 1961.

RaAijmakers, Janneke. The Making of the Monastic Community of Fulda, c. 744-c. 900. Cambridge: Cambridge University Press, 2012.

Rath, Gebhard y Reiter, Erich. Das älteste Traditionsbuch des Klosters Mondsee. Linz: Oberösterreichisches Landesarchiv, 1989.

Sandmann, Mechthild. "Wirkungsbereiche fuldischer Mönche». En Schmid, Karl (ed.). Die Klostergemeinschaft von Fulda im früheren Mittelalter. 2.2. Untersuchungen. München: Fink, 1978, pp. 693-792.

Schwind, Fred. «Beobachtungen zur inneren Struktur des Dorfes in karolingischer Zeit». En Jankhun, Herbert et al. (ed.). Das Dorf der Eisenzeit und des frühen Mittelalters. Göttingen: Vandenhoeck \& Ruprecht, 1977, pp. 444-493.

Seebold, Elmar. Chronologisches Wörterbuch des deutschen Wortschatzes. Der Wortschatz des 8. Jahrhunderts (und früheren Quellen). Berlin-New York: De Gruyter, 2001.

Seebold, Elmar. Chronologisches Wörterbuch des deutschen Wortschatzes. 2. Der Wortschatz des 9. Jahrhunderts. Berlin-New York: De Gruyter, 2008.

Selzer, Wolfgang. "Der Grundbesitz des Klosters Lorsch». En Laurissa Jubilans. Festschrift zur 1200-Jahrfeier von Lorsch. Lorsch: Gemeinde Lorsch, 1964, pp. 64-70.

Sonderegger, Stefan. «Die althochdeutsche Lex Salica-Übersetzung». En Laufner, Richard (ed.). Festgabe für Wolfgang Jungandreas zum 70. Geburtstag am 9. Dezember 1964. Beiträge zur deutschen Sprachgeschichte, Landes-, Volks- und Altertumskunde. Trier: Neu, 1964, pp. 113-122.

SPRANDEL, Rolf. «Die frühmittelalterliche Grundbesitzverteilung und Gerichtsordnung im fränkischen und alemannischen Raum». En Quarthal, Franz (ed.). Alemannien und Ostfranken im Frühmittelalter. Bühl-Baden: Konkordia, 1984, pp. 47-59.

STAAB, Franz. "Aspekte der Grundherrschaftsentwicklung von Lorsch vornehmlich aufgrund der Urbare des Codex Laureshamensis». En Rösener, Werner (ed.). Strukturen der Grundherrschaft im frühen Mittelalter. Göttingen: Vandenhoeck \& Ruprecht, 1993, pp. 285-334. 
ESCRIBIR EL ESPACIO ENTRE LA AUCTORITAS, LA LENGUA HABLADA Y EL RÉGIMEN AGRARIO: CAMPUS EN LOS FONDOS DOCUMENTALES DE WISSEMBOURG, LORSCH Y FULDA...

Steinmeyer, Elias y Sievers, Eduard. Die althochdeutschen Glossen. 1. Glossen zu biblischen Schriften. Berlin: Weidmann, 1879.

Stengel, Edmund Ernst. Urkundenbuch des Klosters Fulda. Marburg: Philipps-Universität Marburg, 1956-1958.

Stengel, Edmund Ernst. «Über die karlingischen Cartulare des Klosters Fulda (Fuldensia II)». En STENGel, Edmund Ernst. Abhandlungen und Untersuchungen zur Hessischen Geschichte. Marburg: Elwert, 1960, pp. 147-193.

Tiefenbach, Heinrich. "Bezeichnungen für Fluren im Althochdeutschen, Altsächsischen und Altniederfränkischen». En BECK, H. et al. (eds.). Untersuchungen zur eisenzeitlichen und frühmittelalterlichen Flur in Mitteleuropa und ihrer Nutzung. Göttingen: 1980, pp. 287-322.

VIADER, Roland. "Introduction». Annales du Midi (= Vigueries et autres circonscriptions intermédiaires du haut Moyen Âge, dir. Roland Viader), 2009, vol. 121, pp. 149-157.

Wartmann, Hermann. Urkundenbuch der Abtei Sanct Gallen I (700-840). Zürich: Höhr, 1863.

WeIDINGER, Ulrich. Untersuchungen zur Wirtschaftsstruktur des Klosters Fulda in der Karolingerzeit. Stuttgart: Hiersemann, 1991.

Wicкнам, Chris. Framing the Early Middle Ages. Europe and the Mediterranean, 400-800. Oxford: Oxford University Press, 2005.

Widemann, Josef. Die Traditionen des Hochstifts Regensburg und des Klosters St. Emmeram. München: Beck, 1943.

Zatscheк, Heinz. «Die Benutzung der Formulae Marculfi und anderer Formularsammlungen in den Privaturkunden des 8. bis 10. Jahrhunderts». Mitteilungen des Österreichischen Instituts für Geschichtsforschung, 1927, vol. 42, pp. 165-267.

Zeumer, Karl (ed.). «Marculfi Formulae». En Formulae Merowingici et Karolini aevi, MGH, Legum sectio V. Hannover: Hahn, 1886.

ZimmermanN, Michel. «Glose, tautologie ou inventaire? L'énumération descriptive dans la documentation catalane du $\mathrm{x}^{\mathrm{e}}$ au $\mathrm{XII}^{\mathrm{e}}$ siècle». Cahiers de Linguistique Hispanique Médiévale, 1989, vol. 14-15, pp. 309-338.

Zimmermann, Michel. Ecrire et lire en Catalogne (IX'-XII siècle). Madrid: Casa de Velázquez, 2003. 